\title{
Molecular Response of the Brain to Cross-Generational Warming in a Coral Reef Fish
}

\author{
Moisés A. Bernal ${ }^{1 *}$, Elliott Schmidt ${ }^{2}$, Jennifer M. Donelson², Philip L. Munday ${ }^{2}$ and \\ Timothy Ravasi ${ }^{2,3}$
}

${ }^{1}$ Department of Biological Sciences, Auburn University, Auburn, AL, United States, ${ }^{2}$ ARC Centre of Excellence for Coral Reef Studies, James Cook University, Townsville, QLD, Australia, ${ }^{3}$ Marine Climate Change Unit, Okinawa Institute of Science and Technology Graduate University, Onna-son, Japan

\section{OPEN ACCESS}

Edited by:

Manuel Aranda,

King Abdullah University of Science and Technology, Saudi Arabia

Reviewed by: Kyle Wellband,

Laval University, Canada Melanie Heckwolf,

Smithsonian Tropical Research Institute, Panama

*Correspondence: Moisés A. Bernal mab0205@auburn.edu

Specialty section: This article was submitted to Marine Molecular Biology and Ecology,

a section of the journal

Frontiers in Marine Science

Received: 27 September 2021

Accepted: 01 February 2022

Published: 04 March 2022

Citation:

Bernal MA, Schmidt E,

Donelson JM, Munday PL and Ravasi $T$ (2022) Molecular Response of the Brain to Cross-Generational

Warming in a Coral Reef Fish.

Front. Mar. Sci. 9:784418. doi: 10.3389/fmars.2022.784418
Ocean warming is a threat to marine biodiversity, as it can push marine species beyond their physiological limits. Detrimental effects can occur when marine poikilotherms are exposed to conditions beyond their thermal optima. However, acclamatory mechanisms, such as plasticity, may enable compensation of detrimental effects if warming is experienced during development or across generations. Studies evaluating the molecular responses of fishes to warming have mostly focused on liver, muscle, and gonads, and little is known about the effects on other vital organs, including the brain. This study evaluated the transcriptional program of the brain in the coral reef fish Acanthochromis polyacanthus, exposed to two different warming scenarios: $+1.5^{\circ} \mathrm{C}$ and $+3.0^{\circ} \mathrm{C}$, across successive generations. Fish were exposed to these conditions in both developmental (F1 and F2) and transgenerational settings (F2 only), as well as a treatment with step-wise warming between generations. The largest differences in gene expression were between individuals of the first and second generation, a pattern that was corroborated by pairwise comparisons between Control F1 and Control F2 (7,500 DEGs) fish. This large difference could be associated with parental effects, as parents of the F1 generation were collected from the wild, whereas parents of the F2 generation were reared in captivity. A general response to warming was observed at both temperatures and in developmental and transgenerational treatments included protein folding, oxygen transport (i.e., myoglobin), apoptosis and cell death, modification of cellular structure, mitochondrial activity, immunity and changes in circadian regulation. Treatments at the highest temperature showed a reduction in synaptic activity and neurotransmission, which matches previous behavioral observations in coral reef fishes. The Transgenerational $+3.0^{\circ} \mathrm{C}$ treatment showed significant activation of the gene pls3, which is known for the development of neuro-muscular junctions under heat-stress. F2 samples exposed to step-wise warming showed an intermediate response, with few differentially expressed genes compared to developmental and transgenerational groups (except for Transgenerational $+1.5^{\circ} \mathrm{C}$ ). In combination with previous studies on liver gene expression, this study indicates that warming produces a molecular signature of stress response in A. polyacanthus that is influenced both by the intensity of warming as well as the duration of exposure.

Keywords: climate change, gene expression, ocean warming, parental effects, phenotypic plasticity, poikilotherms 


\section{INTRODUCTION}

Global warming is one of the most pressing threats to marine ecosystems as a large proportion of marine species are poikilotherms, whose rates of cellular processes depend directly on the temperature of their surrounding environment (Fry, 1967; Huey and Kingsolver, 1989; Cossins, 2012). Hence, small changes in environmental temperature can have detrimental effects on the cellular physiology of marine species, leading to challenges on their metabolism, reproduction, growth, development and physical condition (Munday et al., 2008; Somero, 2010; Schulte et al., 2011; Dahlke et al., 2020). Because of these impacts, multiple studies have focused on understanding potential mechanisms that can allow organisms to cope with such changes, and many of these have explored the relationship between temperature and aerobic metabolic rate (Pörtner and Knust, 2007; Pörtner and Farrell, 2008; Eliason et al., 2011; Alfonso et al., 2021). Among the possible adaptive mechanisms, phenotypic plasticity has been identified as a key means to provide physiological compensation that could potentially keep pace with the rate of projected environmental change (reviewed by: Torda et al., 2017; Fox et al., 2019; Sandoval-Castillo et al., 2020).

There are numerous examples of phenotypic plasticity in marine organisms exposed to elevated temperatures as adults (i.e., reversibly plasticity; e.g., Robinson and Davison, 2008; Bilyk and DeVries, 2011; McArley et al., 2017), and juveniles (developmental plasticity; e.g., Grenchik et al., 2013; Madeira et al., 2016; Warren et al., 2017), as well as when their parents/grandparents have been exposed to similar conditions (parental effects or transgenerational plasticity; Salinas and Munch, 2012; Burgess and Marshall, 2014; Shama et al., 2014; Ross et al., 2016). While some species have demonstrated capacity to fully compensate for environmental change within a generation, greater plasticity has been more commonly observed for species that naturally experience high levels of environmental change in short time scales (i.e., days to weeks; Stillman, 2004; da Silva et al., 2019). Meanwhile, species that have limited capacity for reversible plasticity as adults may require experience of environmental change during critical windows of early ontogeny (Nilsson et al., 2010; Grenchik et al., 2013; Beaman et al., 2016; Madeira et al., 2016). Further, emerging research is showing that shorter timeframe experiments may not accurately predict the capacity for plastic responses to global warming (Munday et al., 2013; He et al., 2021), and aerobic compensation to elevated temperatures may only be observed when warming is experienced across multiple generations (Donelson et al., 2012). This has led to increasing interest in how within and across generation plasticity differs, as well as the corresponding molecular mechanisms associated with the response to warming.

Molecular plasticity in response to elevated temperature can vary by species and the tissue types investigated, yet some common patterns have been described. Pathways associated with oxygen uptake and oxidative stress, mitochondrial activity, activation of electron-transport chain, and corresponding cellular stress responses (tumor suppression, cytoskeleton remodeling, apoptosis) are activated in fish exposed to elevated temperatures (Podrabsky and Somero, 2004; Long et al.,
2012; Madeira et al., 2013,2017; Rebl et al., 2018; Bernal et al., 2020). The molecular responses are also influenced by the timing of exposure, as analyses of developmental and transgenerational treatments show differences in the molecular pathways being activated. Previous studies have observed differences in the expression of genes associated with fatty acid metabolism, protein and carbohydrate metabolism, immunity, organogenesis, and cellular organization between developmental and transgenerational warming (Veilleux et al., 2015; Bernal et al., 2018). Nevertheless, studies that have evaluated the molecular responses of fishes to elevated temperature have primarily focused on liver (Podrabsky and Somero, 2004; Veilleux et al., 2015; Bernal et al., 2018, 2020; Rebl et al., 2018), muscle (Madeira et al., 2017), and gonad tissue (Veilleux et al., 2018). Given the central role of the brain in regulating physiological processes and responding to environmental disturbances (Kotrschal et al., 1998), exploring the molecular responses of the brain to elevated temperature could yield important insights into developmental and transgenerational thermal plasticity.

The effect of water temperature on fish brains has been explored previously by studying traits such as reproduction, behavior and cognitive abilities of fishes. The brain plays an essential role in the regulation of these biological processes through the establishment of endocrine status (Kah et al., 1993; Pankhurst and Munday, 2011), partnership and synchronization of spawning (Kah et al., 1993), learning and cognition (Braithwaite, 2006), choice and preference (Cummings, 2015), and social interactions (Winberg et al., 1996). Changes in environmental temperature can alter the behavior of marine fishes (Allan et al., 2015; Rey et al., 2015; Warren and McCormick, 2019; Angiulli et al., 2020; da Silva-Pinto et al., 2020; Babkiewicz et al., 2021), and these traits could be associated with differences in gene expression. For example, gene expression in zebrafish brains shows that elevated temperatures can impact the cytoarchitecture, metabolism, intracellular communication, cellular transport, and calcium binding (Toni et al., 2019; Nonnis et al., 2021). These changes in turn promote the impairment of sensory perception, motor control, behavioral patterns, and general cognitive performance (Toni et al., 2019; Nonnis et al., 2021). Studies have also shown that elevated temperature can alter gene expression involved in the endocrine system. For example, high temperature suppressed follicle stimulating hormone subunit beta (FSH- $\beta$ ), luteinizing hormone (LH), and gonadotropin releasing hormone (GnRH1 and GnRH-R) gene expression (Okuzawa and Gen, 2013) in red seabream. Considering the critical and diverse role of the brain, it is necessary to explore the molecular responses of this tissue to projected ocean warming.

The spiny chromis damselfish, Acanthochromis polyacanthus, is one of the most studied tropical marine vertebrates in the context of climate change. Previous studies in this species have reported phenotypic and molecular evidence of aerobic and reproductive compensation when warm conditions are maintained across generations (Donelson et al., 2012, 2016; Bernal et al., 2018). Transcriptomic analyses in liver tissue have shown that individuals acutely exposed to warm temperatures show activation of mitochondrial activity, mechanisms of 
cellular stress, apoptosis and inflammation, and immune response (Veilleux et al., 2015; Bernal et al., 2018). Meanwhile, transgenerational lineages have shown upregulation of pathways associated with growth, protein synthesis and oxygen transport (Veilleux et al., 2015; Bernal et al., 2018). Most of this evidence, however, comes from patterns of liver gene expression, which has shown considerable association with measurements of oxygen consumption, especially respiration at rest. Questions remain regarding the generality of these responses across other organs in the context of acute, developmental and transgenerational exposure to warm conditions. Here we evaluate the molecular responses in the brain of F1 and F2 adult spiny chromis exposed to two end-of-century scenarios of warming: $+1.5^{\circ} \mathrm{C}$ and $+3.0^{\circ} \mathrm{C}$. Previous work on the species has evaluated the effect of elevated temperature on the brain and the links to reproductive processes, measuring the expression of candidate genes, showing that FSH- $\beta$ was the only gene exhibiting significant differences across treatments, and was downregulated in females exposed to warm temperatures (Veilleux et al., 2018). Additional studies on brain gene expression have evaluated the response to elevated $\mathrm{CO}_{2}$, where pathways related with glucose metabolism were activated in all treatments, and genes associated with circadian regulation and GABA receptors were differentially expressed between offspring of tolerant and sensitive parents (Schunter et al., 2016). Given that environmental temperature can induce broad changes in the brain function in fishes, it is essential to evaluate these responses through developmental and transgenerational settings.

For this study, we evaluated the molecular responses of the brain of $A$. polyacanthus associated with developmental and transgenerational exposure to elevated temperature. The hypotheses for this study were: brain gene expression will be directly influenced by the level of temperature increase (i.e., Control vs. $+1.5^{\circ} \mathrm{C}$ and $+3.0^{\circ} \mathrm{C}$ ), and developmental vs. transgenerational exposure will lead to the activation of different molecular pathways (i.e., duration of exposure also influences brain gene expression). Based on previous studies in fishes, we also expect that temperature will have a detrimental effect on synaptic activity and neurotransmission (Friedlander et al., 1976; Toni et al., 2019; Nonnis et al., 2021). Considering previous results in liver gene expression for this species, we expect to see activation of mechanisms related with cellular stress response, metabolism of reactive oxygen species, immunity, apoptosis and mitochondrial activity (Veilleux et al., 2015; Bernal et al., 2018). These results expand our understanding on the effects of warming in marine fishes, which is essential for elucidating a more complete picture of the responses of tropical species in a changing planet.

\section{MATERIALS AND METHODS}

\section{Experimental Design and Sampling}

This research study focused on the coral reef damselfish, Acanthochromis polyacanthus, which is widespread throughout the Indo-Australian archipelago $\left(15^{\circ} \mathrm{N}-26^{\circ} \mathrm{S}\right.$ and $116^{\circ} \mathrm{E}-169^{\circ} \mathrm{E}$; Randall et al., 1997). Also known as the spiny chromis,
A. polyacanthus juveniles undergo direct development and parents brood their young (Pankhurst et al., 1999). To begin this multigenerational experiment in 2007, eight pairs of adult fish were collected from the Palm Island region $\left(18^{\circ} 37 \mathrm{~S}, 146^{\circ} 30 \mathrm{E}\right)$ of the central Great Barrier Reef (Donelson et al., 2010). At that time, the region experienced a mean annual temperature range of 23.2-28.5 ${ }^{\circ} \mathrm{C}$ (Australian Institute of Marine Science temperature loggers 1999-2008 at 6-8 $\mathrm{m}^{1}$ ). The wild-caught adult fish were maintained in $60 \mathrm{~L}$ aquaria at James Cook University under current-day summer water temperatures during the Austral summer of $2007-2008\left(28.5^{\circ} \mathrm{C}\right.$ on average). Breeding pairs produced F1 offspring that were divided into three seasonally cycling temperature treatments shortly after hatching (Figure 1; see Donelson et al., 2011, 2014, 2016). These treatments included a current-day control treatment $\left(+0^{\circ} \mathrm{C}\right)$, which followed the average seasonal temperature cycle experienced by fish at the collection area, and two elevated temperature treatment that matched projections for ocean warming by mid $\left(+1.5^{\circ} \mathrm{C}\right)$ and end of the century $\left(+3.0^{\circ} \mathrm{C}\right)$ for the Great Barrier Reef (Lough, 2007; Hobday and Lough, 2011; Pachauri et al., 2015). The darklight cycle was also matched weekly to seasonal changes in day length for the collection location.

F1 fish were kept in sibling groups in $40 \mathrm{~L}$ aquaria until 1 year after hatching, at which time the individuals were separated into pairs. At 1.5 years fish were reorganized into non-sibling heterosexual pairs of the same treatment and of a similar size in preparation for breeding (as described in Donelson et al., 2014). Treatments included Control $+0^{\circ} \mathrm{C}$, Developmental $+1.5^{\circ} \mathrm{C}$ and Developmental $+3.0^{\circ} \mathrm{C}$. During the Austral summer of 2009-2010 (i.e., 2 years of age), these non-sibling F1 pairs were

${ }^{1}$ http://data.aims.gov.au/

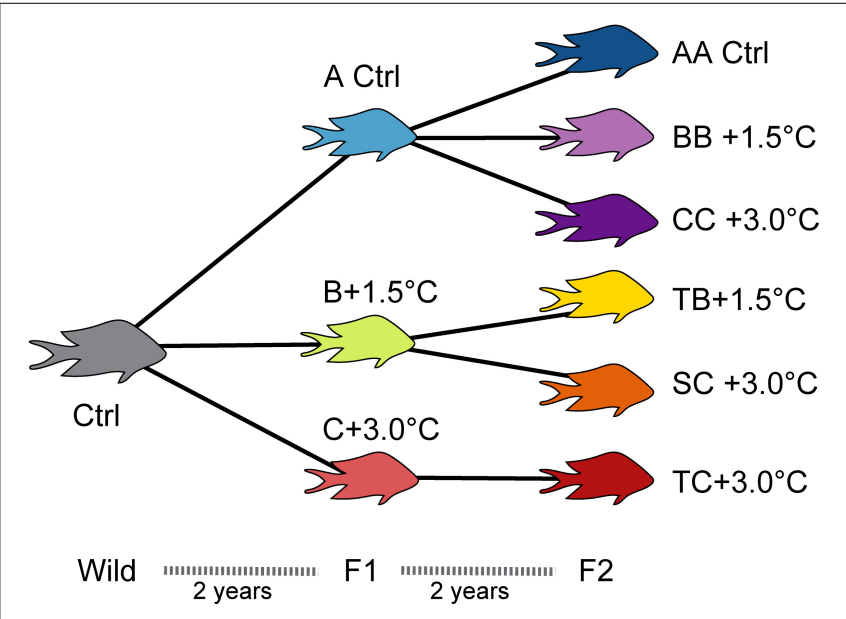

FIGURE 1 | Experimental design for thermal treatments in Acanthochromis polyacanthus. Wild adults were kept in aquaria at Control (Ctrl) conditions (i.e., Austral summer) at $28.5^{\circ} \mathrm{C}$. Control treatments are represented by the letter $\mathrm{A}$, $+1.5^{\circ} \mathrm{C}$ are represented by $\mathrm{B}$, and $+3.0^{\circ} \mathrm{C}$ are represented by the letter $\mathrm{C}$. "TB" $\left(+1.5^{\circ} \mathrm{C}\right)$ and "TC" $\left(+3.0^{\circ} \mathrm{C}\right)$ represent transgenerational treatments of the $\mathrm{F} 2$, and "sC" represents the stepwise warming treatment $\left(+1.5^{\circ} \mathrm{C}\right.$ in $\mathrm{F} 1$ and $+3.0^{\circ} \mathrm{C}$ in F2). 
mature, reproductively active, and produced F2 juveniles. These F2 juveniles underwent embryonic development and hatched at the same temperature as the F1 parents. Following hatching all treatments continued to be reared in these same conditions. Newly hatched F2 juveniles from F1 Control $+0^{\circ} \mathrm{C}$ parents were also transferred to both +1.5 and $+3.0^{\circ} \mathrm{C}$ treatment conditions on the day of hatching to produce developmental treatments with the F2 generation (Figure 1). Juveniles produced by F1 $+1.5^{\circ} \mathrm{C}$ parents were also transferred to $+3.0^{\circ} \mathrm{C}$ conditions on the day of hatching, for the Step $+3.0^{\circ} \mathrm{C}$ treatment. This resulted in six treatments within the $\mathrm{F} 2$ generation; F2 Control $+0^{\circ} \mathrm{C}$, F2 Developmental $+1.5^{\circ} \mathrm{C}$ and F2 Developmental $+3.0^{\circ} \mathrm{C}$, F2 Transgenerational $+1.5^{\circ} \mathrm{C}$, Transgenerational $+3^{\circ} \mathrm{C}$ and Step $+3.0^{\circ} \mathrm{C}$ (Figure 1). Across all generations, fish were fed a stagespecific commercial fish food (INVE NRD 2/4, 5/8 or G12, Primo Aquaculture, Narangba, QLD, Australia). In all generations and all treatments mortality was low (estimated at $<5 \%$ ). Density reduction through time (outlined above) was conducted per sibling tank to allow similar numbers of each breeding line to be available for reproductive pairs. The only evidence of possible selection observed across the generations was seen in the $\mathrm{F} 1$ Developmental $+3^{\circ} \mathrm{C}$ line, where there was a bias toward a reproductive pair from the F0 (Pair 41; Donelson et al., 2012). The sex of all the sampled individuals is available in Supplementary Table 1, while the details of the breeding pairs for the F1 and F2 generations are available in Supplementary Tables 2, 3, respectively.

This research was conducted under the James Cook University animal ethics approvals A1233, A1415, and A1547. The original collection of wild fish in 2007 was completed under Great Barrier Reef Marine Park Permit G06/20234.1 and Queensland Fisheries Permit 103256.

\section{RNA Library Preparation and Sequencing}

Individuals from the F1 generation were sampled in March through June 2010. Meanwhile the F2 generation was sampled between the last week of March and first week of April 2012. For both generations, this represented a period of $\sim 2$ years between the time of hatching and the time of sampling. Whole brains of the F1 and F2 generations were frozen in liquid nitrogen and homogenized for extraction immediately after euthanasia. The RNA extractions were done with the RNeasy Mini kit (Qiagen) following manufacturer's instructions. Final RNA extractions yielded between 0.5 and $2.5 \mu \mathrm{g}$ of total RNA, and the RNA integrity number (RIN) was higher than seven (Austral summer of 2011-2012). After quality control, the total number of samples per treatment were: F1 Control $n=6, \mathrm{~F} 1$ Developmental $+1.5^{\circ} \mathrm{C} n=6$, developmental $+3^{\circ} \mathrm{C} n=6$; F2 Control $n=6$, F2 Developmental $+1.5^{\circ} \mathrm{C} n=5$, developmental $+3^{\circ} \mathrm{C} n=6$, F2 Transgenerational $+1.5^{\circ} \mathrm{C} n=4$, F2 Step $+3^{\circ} \mathrm{C}$ $n=5, \mathrm{~F} 2$ Transgenerational $+3.0^{\circ} \mathrm{C} n=5$. The RNAseq libraries for brain gene expression were prepared with the Illumina TruSeq RNA kit, at Macrogen Inc., South Korea. The sequencing of these fragments was conducted by the same facility using an Illumina Hiseq4000 (150 bp PE), where 11 to 12 samples were sequenced per lane (target was $\sim 50$ million reads per sample). To avoid having confounding effects of sequencing bias on the analyses of differential expression, no more than two samples of one treatment were sequenced in the same Illumina lane. Raw sequences for all samples are available in NCBI BioProject PRJNA768249.

\section{Data Processing and Statistical Analyses}

The program Cutadapt 1.13 (Martin, 2011) was used for removing the TruSeq Illumina adaptors, low-quality treads $(Q<30)$, and reads shorted than $50 \mathrm{bp}$. The program HISAT2 2.0.5 (Kim et al., 2015) was used to map the clean reads to the chromosome-scale genome of A. polyacanthus (ENSMBL ASM210954v1; GenBank Assembly ID GCA_002109545). This step also filtered the reads so that only regions that had both pairs successfully aligned to the reference were retained for downstream analyses. The RNA-Seq reads were summarized as read counts per transcript using the featureCounts function of the Subreads Package 1.6.1 (Liao et al., 2014), setting the mapping quality (Q) to five.

The analyses of differential gene expression were conducted using DeSeq2 1.33 (Love et al., 2014) in RStudio ( $\mathrm{R}$ Core Team, 2013). To evaluate the presence of outlier samples in the analysis of gene expression, a heatmap of sample distance based on the raw data was created. This resulted in the removal of one of the Control samples from the F1 from the analysis. To understand the effect of experimental conditions on brain gene expression, a likelihood ratio test (LRT) was conducted. Here, all samples were assigned to different categories based on whether they corresponded to the F1 or F2 generation, the temperature at which they were exposed during development (i.e., $+0^{\circ} \mathrm{C},+1.5^{\circ} \mathrm{C}$ or $+3.0^{\circ} \mathrm{C}$ ), the moment when samples were exposed to the experimental conditions (i.e., developmental or transgenerational) their sex (Supplementary Table 1), and the F0 breeding pairs (Supplementary Tables 2, 3). The models tested were the effect of all variables combined (i.e., temperature, generation, time of exposure, F0 pairs and sex), as well as the effect of an individual variable excluding the effect of the other variables (i.e., effect of temperature controlling for generation, sex, F0 breeding pairs, and experimental condition). Genes were considered to be differentially expressed based on an adjusted $p$-value of $<0.05$ after BenjaminiHochberg correction. A principal coordinate analysis (PCoA) was done for the variance stabilized counts of the differentially expressed genes (padj. < 0.05) of the LRT analysis for the F1 (110 DEG) and the F2 (118 DEG) separately. To assess differences associated with the intensity of warming $\left(+1.5^{\circ} \mathrm{C}\right.$ or $+3.0^{\circ} \mathrm{C}$ ) as well as length of warming exposure (developmental and transgenerational), pairwise comparisons of all individual treatments in the F1 and F2 were also conducted. This was done with the "Contrast" function of DESeq2, where differential expression was considered if padj. $<0.05$ after BenjaminiHochberg correction. The custom scripts used for the analyses of gene expression are available at: https:/github.com/evofish/f2brains.

The results generated from the pairwise comparisons in the analysis of gene expression were used to determine if there was significant enrichment of Gene Ontology (GO) categories using the Mann-Whitney $U$ test, with a Benjamini-Hochberg 
correction (GO-MWU'; Wright et al., 2015). This analysis was conducted separately for each of the GO categories: Biological Process (BP), Cellular Component (CC), and Molecular Function (MF). For the analysis, the Log2Fold Change of all genes in the pairwise comparison was used as input data, and the GO-MWU test determines if genes that belong to a specific GO category are over-represented at the top (upregulated) or at the bottom (downregulated) of the distribution of all genes. Further, GO terms are collapsed into one if they have more than $75 \%$ of similarity in their composition. This test differs from the Fisher's test of enrichment, where significant DEGs are compared to the full list of genes present in the transcriptome. Hence, the GO-MWU test provides an advantage over the Fisher's test, as it does not require previous knowledge of significant genes to estimate the overrepresented functions (Wright et al., 2015). GO categories were considered enriched if they included more than five terms and passed a 10\% FDR after the Benjamini-Hochberg correction. The GO enrichment analysis process was conducted through an automated process in R, whereby different treatment comparisons were looped through the MWU analysis. The automation process involved isolating the necessary data (GO terms and log2FoldChange), the removal of NA's, and exporting of processed data into a set directory whereby data frames can then be run through an automated (for) loop that integrates the initial code from the MWU analysis designed by Wright et al. (2015). The script for the automation of the pipeline can be found at https://github.com/schmidte10/GO-MWU-automation-.

\section{RESULTS}

The mapping success of the filtered RNA-seq reads to the A. polyacanthus genome using HISAT2 was between 82 and $90 \%$. After mapping, the analysis of gene expression with DESeq2 indicated that one sample from F2 Control was a statistical outlier in terms of the number of reads, and this sample was eliminated from the analyses (F2 Control $n=5$ ). The total counts for the gene expression analyses were between 29,036,187 and 56,488,723, with an average of 41,477,978.

\section{Overarching Drivers of Differential Expression}

The largest difference in brain gene expression was observed between generations (F1 vs. F2), which resulted in 11,060 DEGs with padj. $<0.05$ (for comparison 9,781 DEGs with padj. $<0.01$ ). This result was surprising, given that both groups were sampled around the same age (i.e., 2 years) and the same time in the year (late austral summer). To explore this further a pairwise comparison was made between the Control F1 vs. Control F2 treatments (i.e., removing the effects of temperature), resulting in 7,550 DEGs (Table 1), most of which were also differentiated in the LRT between generations (6,326 DEGs). Here GO categories related with neurotransmission and synaptic activity ("Signal release from synapse," "Presynaptic active zone," "G proteincoupled GABA receptor activity," "Voltage-gated sodium channel

\footnotetext{
${ }^{2}$ https://github.com/z0on/GO_MWU
}

activity"), cellular proliferation and organization ("Sphingosine1-phosphate receptor activity"), and signal transduction ("SMAD binding," "Regulation of antigen receptor-mediated signaling pathway," "Bioactive lipid receptor activity") were activated in Control F1. Meanwhile GO categories related with electron transport chain ("NADH dehydrogenase ubiquinone activity," "Respiratory electron transport chain," "Heme-copper terminal oxidase activity") and transmembrane transport ("Ubiquinolcytochrome-c reductase activity," "Bile acid: sodium symporter activity") were the most highly activated in the Control F2. Considering that large differences were observed even in the Control treatments across the different generations, these results suggests that there is a transgenerational effect of captivity on brains of a coral reef fish.

Temperature was the second dominant factor in terms of differential expression, with 362 DEGs between samples exposed to Control, $+1.5^{\circ} \mathrm{C}$ and $+3.0^{\circ} \mathrm{C}$ (Figure 2). Another factor that played a considerable role was the effect of grandparents, as these resulted in 268 DEGs. There were 32 DEGs associated with the stage at which the increased experimental temperature was applied (i.e., developmental or transgenerational). For the latter, the Step treatment was considered a developmental group (Figure 1). Finally, there were eight DEGs associated with sex, and this relatively small number of genes is relevant considering the higher proportion of females in the F2. Because the large differences in gene expression between the F1 and F2 generation could be associated with parental effects of captivity (i.e., the differential effects of the F1 generation having wild-caught parents whereas the F2 generation had captive-reared parents), the rest of the pairwise comparisons were only conducted between individuals of the same generation.

\section{Pairwise Comparisons}

A summary of the DEG and GO enrichment from the pairwise comparisons is displayed in Table $\mathbf{1}$ and Figure 3. The complete set of DEGs for all comparisons is available in Supplementary Data 1, while all GO enriched categories are in Supplementary Data 2. There were three comparisons conducted among the F1 generation and 11 comparisons conducted among the F2 treatments, for evaluating differences associated with the intensity of warming as well as the consequences of the time of exposure to elevated temperatures (developmental and transgenerational treatments). In general, F2 comparisons resulted in fewer DEG compared to the F1 (Table 1). Specific responses of the developmental and transgenerational categories, as well as their overlap are delineated below.

\section{Developmental Comparisons}

The comparison of the F1 Control and F1 Developmental $+1.5^{\circ} \mathrm{C}$ resulted in $122 \mathrm{DEGs}$, with genes associated with growth and development of brain (Somatotropin; Nuclear receptor ROR-beta) and organization of microtubules (Ninein) being upregulated in the warm treatment. One of the categories that was most highly activated was "Presynaptic Active Zone," and additional GO terms associated with neurotransmission activated at $+1.5^{\circ} \mathrm{C}$ were "Synaptic vesicle priming," "Regulation of synapse organization," "Neurotransmitter transport." Meanwhile, 
TABLE 1 | Number of differentially expressed genes (DEGs) and significant Gene Ontology (GO) categories between specific thermal comparisons, for each of the GO domains: Biological Process (BP); Cellular Component (CC); and Molecular Function (MF).

\begin{tabular}{|c|c|c|c|c|c|c|}
\hline \multirow[t]{2}{*}{ Comparison } & \multirow[t]{2}{*}{ Direction } & \multirow[t]{2}{*}{ DEG } & \multicolumn{3}{|c|}{ Significant GO terms } & \multirow[t]{2}{*}{ General functions } \\
\hline & & & BP & $\mathrm{CC}$ & MF & \\
\hline \multirow[t]{2}{*}{ Control F1 vs. Control F2 } & Up & 4159 & 33 & 21 & 60 & $\begin{array}{l}\text { Synaptic activity, ion channel activity, cellular signaling, immunity, regulation of transcription, ion transport, } \\
\text { vascular development. }\end{array}$ \\
\hline & Down & 3391 & 91 & 27 & 63 & $\begin{array}{l}\text { Cellular transport, oxidation-reduction, cellular organization, electron transport chain, energy metabolism, } \\
\text { detoxification, metabolism of nucleic acids. }\end{array}$ \\
\hline \multirow[t]{2}{*}{$\begin{array}{l}\text { Control vs. Developmental }+1.5^{\circ} \mathrm{C} \\
\text { (F1) }\end{array}$} & Up & 89 & 46 & 15 & 28 & $\begin{array}{c}\text { Circadian regulation, electron transport, immunity, respiratory chain, stress response, light perception, } \\
\text { hormone activity, oxygen transport. }\end{array}$ \\
\hline & Down & 33 & 34 & 13 & 41 & Synaptic activity, cellular structure, ion channel organization and activity, development. \\
\hline \multirow{2}{*}{$\begin{array}{l}\text { Control vs. Developmental }+3.0^{\circ} \mathrm{C} \\
(\mathrm{F} 1)\end{array}$} & Up & 188 & 8 & 4 & 12 & Cellular signaling, blood coagulation, immunity, protein metabolism, receptor activity. \\
\hline & Down & 61 & 4 & 6 & 5 & Reactive oxygen species, energy metabolism, lipid transport, cellular structure, ionic channels. \\
\hline \multirow[t]{2}{*}{$\begin{array}{l}\text { Developmental }+1.5^{\circ} \mathrm{C} \text { vs. }+3.0^{\circ} \mathrm{C} \\
\text { (F1) }\end{array}$} & Up & 12 & 25 & 10 & 42 & $\begin{array}{c}\text { Development, morphogenesis, transmembrane transport, ion channel activity, signal transduction, } \\
\text { synapsis, response to stimulus. }\end{array}$ \\
\hline & Down & 7 & 51 & 17 & 18 & $\begin{array}{l}\text { Reactive oxygen species metabolism, energy metabolism, circadian regulation, electron transport chain, } \\
\text { mitochondrial activity, protein folding. }\end{array}$ \\
\hline \multirow[t]{2}{*}{$\begin{array}{l}\text { Control vs. Developmental }+1.5^{\circ} \mathrm{C} \\
\text { (F2) }\end{array}$} & Up & 19 & 34 & 20 & 23 & $\begin{array}{l}\text { Circadian regulation, energy metabolism, cellular structure, respiratory chain complex, hormone activity, } \\
\text { immunity, electron transport. }\end{array}$ \\
\hline & Down & 8 & 23 & 8 & 20 & $\begin{array}{l}\text { Cellular signaling, cell migration, cellular organization, cellular structure, ion channel activity, response to } \\
\text { stimulus, development, signal transduction. }\end{array}$ \\
\hline \multirow[t]{2}{*}{$\begin{array}{l}\text { Control vs. Developmental }+3.0^{\circ} \mathrm{C} \\
\text { (F2) }\end{array}$} & Up & 139 & 18 & 8 & 25 & $\begin{array}{l}\text { Heart rate regulation, appetite regulation, behavior, energy regulation, ion channels, cellular signaling, } \\
\text { neurotransmitter activity. }\end{array}$ \\
\hline & Down & 48 & 28 & 9 & 11 & $\begin{array}{l}\text { Serine/threonine kinase signaling, cellular structure, oxidation-reduction, nucleic acid metabolism, DNA } \\
\text { replication, response to stimulus, protein metabolism. }\end{array}$ \\
\hline \multirow[t]{2}{*}{ Control vs. Step $+3.0^{\circ} \mathrm{C}(\mathrm{F} 2)$} & Up & 23 & 21 & 4 & 30 & $\begin{array}{l}\text { Circadian regulation, synaptic activity, regulation of neurotransmitters, behavior, ion channel activity, } \\
\text { transporter activity. }\end{array}$ \\
\hline & Down & 25 & 34 & 6 & 15 & $\begin{array}{l}\text { Calcium transport, cellular structure, lipid metabolism, transmembrane receptors, oxidation-reduction, } \\
\text { metabolism of nucleic acids, response to stimulus and stress. }\end{array}$ \\
\hline \multirow[t]{2}{*}{$\begin{array}{l}\text { Developmental }+1.5 \text { vs. }+3.0^{\circ} \mathrm{C} \\
(\mathrm{F} 2)\end{array}$} & Up & 3 & 24 & 4 & 26 & $\begin{array}{l}\text { Development, transport across membranes, morphogenesis, development of neurons, regulation of } \\
\text { neurotransmitters, behavior, cellular adhesion, synaptic activity, protein metabolism, cell signaling. }\end{array}$ \\
\hline & Down & 7 & 29 & 6 & 4 & $\begin{array}{l}\text { Circadian regulation, cell differentiation, oxygen transport, ionic channels, metabolism of nucleic acids, } \\
\text { response to stimulus and stress, oxidation-reduction. }\end{array}$ \\
\hline \multirow[t]{2}{*}{$\begin{array}{l}\text { Developmental }+1.5^{\circ} \mathrm{C} \text { vs. Step } \\
+3.0^{\circ} \mathrm{C}(\mathrm{F} 2)\end{array}$} & Up & 7 & 42 & 9 & 50 & $\begin{array}{l}\text { Synaptic activity, ion channel activity, development, axonal structure, cell signaling, neurotransmitter } \\
\text { activity, neuronal structure, organ morphogenesis, signal transduction, response to stimulus. }\end{array}$ \\
\hline & Down & 10 & 60 & 15 & 36 & $\begin{array}{l}\text { Cell differentiation, mitochondrial activity, ion channel activity, protein metabolism, coagulation, } \\
\text { oxidation-reduction, electron transport chain, oxygen binding, immunity, regulation of blood pressure, cell } \\
\text { signaling, energy metabolism, response to stress, metabolism of nucleic acids, mitochondrial activity. }\end{array}$ \\
\hline \multirow[t]{2}{*}{$\begin{array}{l}\text { Developmental }+3.0^{\circ} \mathrm{C} \text { vs. Step } \\
+3.0^{\circ} \mathrm{C}(\mathrm{F} 2)\end{array}$} & Up & 1 & 29 & 12 & 31 & $\begin{array}{l}\text { Circadian regulation, ion channel activity, synaptic activity, cellular signaling, cellular structure, } \\
\text { transcription, transporter activity, signal transduction, chromatin organization. }\end{array}$ \\
\hline & Down & 1 & 28 & 12 & 24 & $\begin{array}{l}\text { Mitochondrial activity, electron transfer activity, protein synthesis, tumor suppression, energy metabolism, } \\
\text { homeostasis, immunity, oxidation-reduction, response to stimulus. }\end{array}$ \\
\hline \multirow[t]{2}{*}{$\begin{array}{l}\text { Control vs. Transgenerational } \\
+1.5^{\circ} \mathrm{C}(\mathrm{F} 2)\end{array}$} & Up & 33 & 33 & 14 & 31 & $\begin{array}{l}\text { Immunity, oxygen binding, neurotransmitter activity, oxidation-reduction activity, behavior, electron } \\
\text { transport chain, lipid metabolism, hormone activity, defense response. }\end{array}$ \\
\hline & Down & 17 & 26 & 16 & 32 & $\begin{array}{c}\text { Cellular structure, serine/threonine kinase, synaptic activity, synapse organization, ion channel activity, ion } \\
\text { transport. }\end{array}$ \\
\hline \multirow[t]{2}{*}{$\begin{array}{l}\text { Control vs. Transgenerational } \\
+3.0^{\circ} \mathrm{C}(\mathrm{F} 2)\end{array}$} & Up & 68 & 13 & 5 & 39 & $\begin{array}{l}\text { Ion transport, circadian regulation, neurotransmitter activity, lipid transport, signaling, cell signaling, } \\
\text { hormonal activity, synaptic activity. }\end{array}$ \\
\hline & Down & 44 & 27 & 5 & 18 & $\begin{array}{l}\text { Oxidation-reduction, cellular structure, protein metabolism, nucleic acid metabolism, response to stress } \\
\text { and stimulus, immunity, chromatin modification, energy metabolism. }\end{array}$ \\
\hline Developmental $+1.5^{\circ} \mathrm{C}$ vs. & Up & 27 & 8 & 3 & 11 & Oxygen transport, response to stimulus, cellular signaling, cell adhesion, immunity. \\
\hline Transgenerational $+1.5^{\circ} \mathrm{C}(\mathrm{F} 2)$ & Down & 11 & 10 & 4 & 16 & $\begin{array}{l}\text { Circadian regulation of gene expression, cellular structure, transmembrane transporter activity, ion channel } \\
\text { activity, synaptic activity. }\end{array}$ \\
\hline \multirow[t]{2}{*}{$\begin{array}{l}\text { Developmental }+3^{\circ} \mathrm{C} \text { vs. } \\
\text { Transgenerational }+3^{\circ} \mathrm{C}(\mathrm{F} 2)\end{array}$} & Up & 18 & 14 & 16 & 38 & $\begin{array}{c}\text { Circadian regulation, cellular structure, ion channel activity, receptor binding, synaptic activity, oxygen } \\
\text { binding, phosphorylation, transmembrane transport, DNA metabolism. }\end{array}$ \\
\hline & Down & 13 & 26 & 15 & 33 & $\begin{array}{l}\text { Activation of immune response, oxidation-reduction, tumor suppression, energy metabolism, electron } \\
\text { transport chain, response to stimulus, immunity, biosynthesis, mitochondrial activity, protein synthesis. }\end{array}$ \\
\hline \multirow[t]{2}{*}{$\begin{array}{l}\text { Transgenerational }+1.5^{\circ} \mathrm{C} \text { vs. Step } \\
+3.0^{\circ} \mathrm{C}(\mathrm{F} 2)\end{array}$} & Up & 46 & 35 & 15 & 52 & $\begin{array}{c}\text { Circadian regulation, ion channel activity, synaptic activity, cellular structure, neuronal organization and } \\
\text { development, ion membrane transport, neurotransmitter activity, serine/threonine kinase, cell } \\
\text { development, cellular signaling, transcription. }\end{array}$ \\
\hline & Down & 103 & 45 & 14 & 52 & $\begin{array}{l}\text { Oxygen binding, gas transport, lipid metabolism, detoxification, oxidation-reduction, signal transduction, } \\
\text { coagulation, immunity, electron transport chain, nucleic acid metabolism, hormonal activity, response to } \\
\text { stimulus, stress response, respiratory chain complex, cell adhesion. }\end{array}$ \\
\hline \multirow{2}{*}{$\begin{array}{l}\text { Transgenerational }+3^{\circ} \mathrm{C} \text { vs. Step } \\
+3.0^{\circ} \mathrm{C}(\mathrm{F} 2)\end{array}$} & Up & - & 2 & 1 & 1 & Cellular structure, nucleic acid metabolism, signal transduction. \\
\hline & Down & 2 & 5 & 3 & 3 & Response to light, oxygen transport, neuronal activity, metabolism of peptides. \\
\hline \multirow[t]{2}{*}{$\begin{array}{l}\text { Transgenerational }+1.5^{\circ} \mathrm{C} \text { vs. } \\
+3.0^{\circ} \mathrm{C}(\mathrm{F} 2)\end{array}$} & Up & 165 & 35 & 16 & 55 & $\begin{array}{l}\text { Circadian regulation, neurotransmitter activity, ion channel activity, transcription, heart rate regulation, cell } \\
\text { signaling, GABA receptors, transmembrane transport, energy metabolism, synaptic activity, cellular } \\
\text { adhesion, cellular structure, protein binding, morphogenesis. }\end{array}$ \\
\hline & Down & 196 & 41 & 16 & 51 & $\begin{array}{l}\text { Immunity, oxidation-reduction, coagulation, catabolism, tumor suppression, channel activity, ATP } \\
\text { synthesis and metabolism, electron transport activity, response to stimulus, chemotaxis, protein folding, } \\
\text { tissue damage, catabolism, protein metabolism. }\end{array}$ \\
\hline
\end{tabular}

The names represent the processes activated by each of the treatments in the pairwise comparisons. The direction of expression (i.e., up or down) is relative to the first mentioned treatment. 

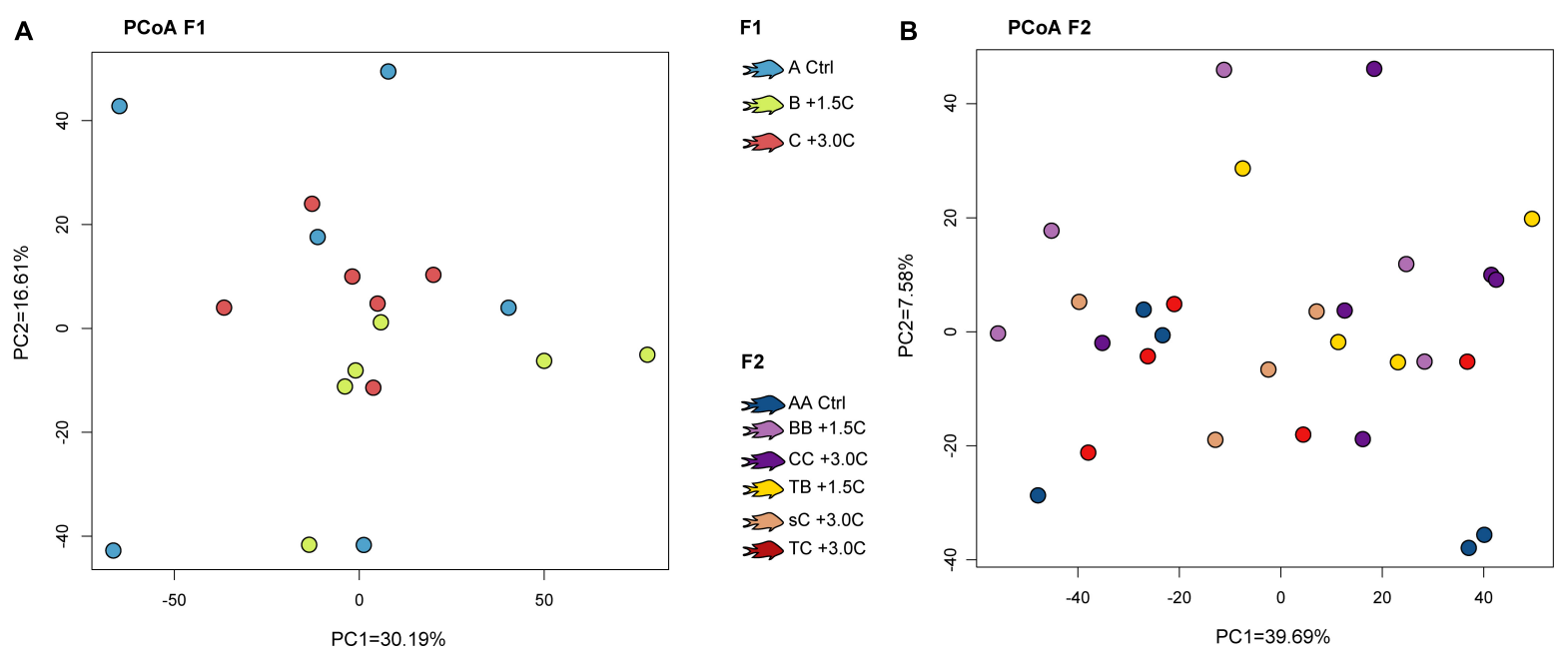

FIGURE 2 | Principal coordinate analysis based on the variance stabilized read counts of the differentially expressed genes by temperature, for the F1 (A) and F2 (B) Colors represent the different thermal treatments. Control treatments are represented by the letter $\mathrm{A},+1.5^{\circ} \mathrm{C}$ are represented by $\mathrm{B}$, and $+3.0^{\circ} \mathrm{C}$ are represented by the letter $\mathrm{C}$. "TB" $\left(+1.5^{\circ} \mathrm{C}\right)$ and "TC" $\left(+3.0^{\circ} \mathrm{C}\right)$ represent transgenerational treatments of the $\mathrm{F} 2$, and "sC" represents the stepwise warming treatment $\left(+1.5^{\circ} \mathrm{C}\right.$ in $\mathrm{F} 1$ and $+3.0^{\circ} \mathrm{C}$ in $\left.\mathrm{F} 2\right)$.

the comparison of F1 Control and F1 Developmental $+3.0^{\circ} \mathrm{C}$ resulted in 249 DEGs, with genes related to photoreception (Fascin-2), circulation (Troponin cardiac muscle; Erythropoietin), and mTOR complex (DEP domain-containing mTOR-interacting) being upregulated in the warm treatment. The F1 Developmental $+3.0^{\circ} \mathrm{C}$ showed highest activation for the GO category "Reactive oxygen species biosynthetic process," and salient categories included "Microtubule motor activity" and "Gated channel activity." The comparison of F1 Developmental $+1.5^{\circ} \mathrm{C}$ with $+3.0^{\circ} \mathrm{C}$ resulted in 27 DEGs, and the GO category "SMAD binding" (associated with signal transduction was activated in $+1.5^{\circ} \mathrm{C}$ ), while the categories "Reactive oxygen species biosynthetic process," "Circadian regulation of gene expression," "Innate immune response," "Mitochondrial respiratory chain" were activated in $+3.0^{\circ} \mathrm{C}$.

The comparison between F2 Control and F2 Developmental $+1.5^{\circ} \mathrm{C}$ showed $27 \mathrm{DEGs}$, with the most activated categories in the warm treatment including "Vascular endothelial growth factor-activated receptor activity," "Hemoglobin Complex," "Positive regulation of BMP signaling pathway," and "Wnt-activated receptor activity." By contrast, "Circadian regulation of expression," "Neuropeptide Hormone Activity" and "Regulation of Appetite" were downregulated in the warm treatment. The comparison between F2 Control and F2 Developmental $+3.0^{\circ} \mathrm{C}$ resulted in $187 \mathrm{DEG}$, with the warm treatment showing activation for regulation of expression ("Covalent chromatin modification," "Transcription regulator activity," "Transcription regulator complex"), DNA replication (DNA metabolic process, DNA replication, Chromosome organization), and protein synthesis ("Protein-containing complex binding," "Protein-DNA complex," "Protein-containing complex subunit organization"). Processes related with energetic balance were downregulated in Developmental $+3.0^{\circ} \mathrm{C}$ when compared to Control (e.g., "ATP metabolic process," "Electron transfer activity," "Generation of precursor metabolites and energy," "Glucose homeostasis," "Regulation of Appetite").

Some of the smallest numbers of DEGs were observed for the comparisons with the Step $+3.0^{\circ} \mathrm{C}$ treatment. Comparing Step $+3.0^{\circ} \mathrm{C}$ with Development $+1.5^{\circ} \mathrm{C}$ resulted in 10 DEGs, Step $+3.0^{\circ} \mathrm{C}$ vs. Developmental $+3.0^{\circ} \mathrm{C} 2$ DEGs, and Step $+3.0^{\circ} \mathrm{C}$ vs. Transgenerational $+3.0^{\circ} \mathrm{C} 2$ DEGs. Meanwhile, the comparison between F2 Control and Step $+3.0^{\circ} \mathrm{C}$ resulted in 48 DEGs. Despite being siblings from the same $\mathrm{F} 1$ crosses, a large number of DEGs were found when comparing the Step $+3.0^{\circ} \mathrm{C}$ with F2 Transgenerational $+1.5^{\circ} \mathrm{C}$ (149 DEGs). Here, Step $+3.0^{\circ} \mathrm{C}$ showed activation of genes related with protection against oxidative stress (Peroxiredoxin-4; Redox-regulatory FAM213A), oxygen transport (Myoglobin; Early growth response 1), cell death (Tumor necrosis factor receptor superfamily member 10B), immunity (Immunoglobulin lambda constant $1 ; \mathrm{H}-2$ class II histocompatibility E-D alpha chain) and cell signaling (GTPbinding GEM; Essential MCU mitochondrial).

\section{Transgenerational Comparisons}

The comparison of F2 Control and F2 Transgenerational $+1.5^{\circ} \mathrm{C}$ resulted in 50 DEGs, which showed activation for categories associated with microtubule organization ("Nuclear membrane microtubule tethering complex") and cell signaling ("Positive regulation of serine/threonine kinase signaling pathway"). GO categories activated in Transgenerational $+1.5^{\circ} \mathrm{C}$ resulted in the activation of synapse regulation and organization, response to stress and external stimuli, sodium and calcium channel activity, and transcription regulation. Notably these processes were all downregulated in Developmental $+1.5^{\circ} \mathrm{C}$ (Table 1 and Supplementary Data 2). Further, the contrast between Developmental and Transgenerational treatments at $+1.5^{\circ} \mathrm{C}$ resulted in 38 DEGs. In this comparison the 


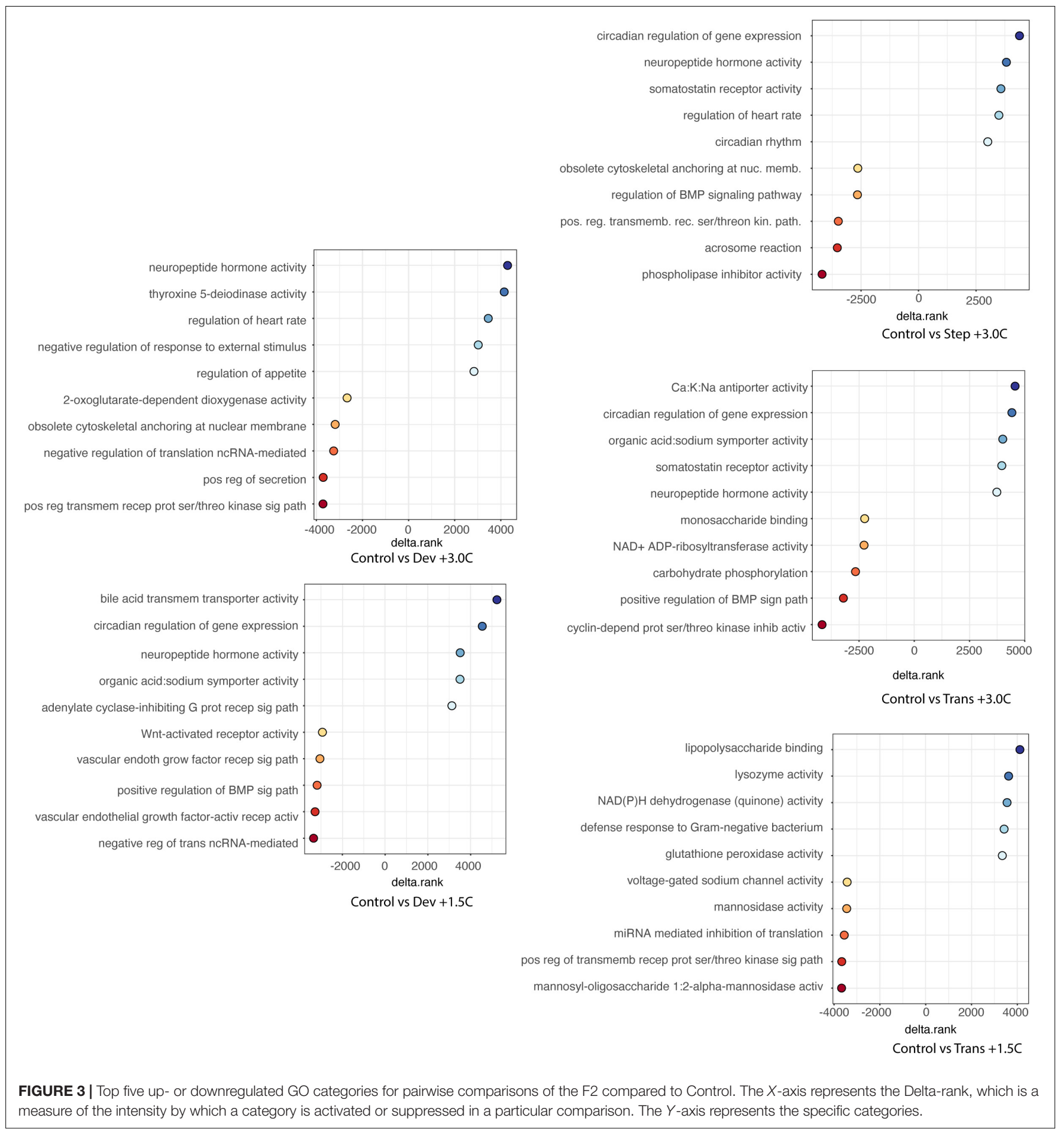

$\mathrm{GO}$ terms upregulated in F2 Developmental $+1.5^{\circ} \mathrm{C}$ were "Oxygen Transport" and "Peptide cross-linking" (i.e., protein modifications), while "Circadian Regulation of Expression" and multiple categories related to ion transport were activated in the F2 Transgenerational $+1.5^{\circ} \mathrm{C}$. The GO term "Hemoglobin Complex" was activated in the Developmental $+1.5^{\circ} \mathrm{C}$ in comparison to Control, while it was downregulated for Transgenerational $+1.5^{\circ} \mathrm{C}$.
The contrast between Control to Transgenerational $+3.0^{\circ} \mathrm{C}$ resulted in 112 DEGs, and GO categories that were activated in the latter were associated with regulation of immune activity, histone modification, response to stress, oxidoreductase activity circadian rhythm, cell signaling and calcium channel activity. Interestingly, multiple terms associated with synapse and circadian regulation were deactivated in the Transgenerational $+3.0^{\circ} \mathrm{C}$ compared to Control (opposite to the trend observed 
in Transgenerational $\left.+1.5^{\circ} \mathrm{C}\right)$. Meanwhile, the contrast between F2 Developmental and Transgenerational treatments at $+3.0^{\circ} \mathrm{C}$ resulted in 31 DEGs. Here the GO categories "Circadian regulation of expression," "Modified amino-acid binding" and "Voltage-gated sodium channel activity" were activated in Developmental $+3.0^{\circ} \mathrm{C}$, while the categories "Arylesterase activity" (i.e., anti-oxidant), "Tumor necrosis factor receptor binding," and "Activation of immune response" were upregulated in Transgenerational $+3.0^{\circ} \mathrm{C}$. The Transgenerational $+3.0^{\circ} \mathrm{C}$ response was also characterized by the activation of the gene Plastin-3, associated with neuro-muscular protection.

The comparison between F2 Transgenerational $+1.5^{\circ} \mathrm{C}$ and $+3.0^{\circ} \mathrm{C}$ resulted in 361 DEGs. The activated $\mathrm{GO}$ categories in Transgenerational $+1.5^{\circ} \mathrm{C}$ included "Circadian regulation of expression," "Voltage-gated sodium channel activity," "Regulation of heart rate." Meanwhile, GO terms activated in Transgenerational $+3.0^{\circ} \mathrm{C}$ included "Lysozyme activity," "Thrombin-activated receptor activity," and "Tumor necrosis factor receptor binding." There were two annotated genes upregulated in the $+1.5^{\circ} \mathrm{C}$ and $+3.0^{\circ} \mathrm{C}$ Transgenerational treatments with respect to Control: Chemokine-like receptor 1 , and Hydroperoxide isomerase ALOXE3, both of which are known to be associated with lipid metabolism in vertebrates.

\section{Overlap in Developmental and Transgenerational Treatments}

There was low overlap in the DEGs activated in the F1 and F2 for the comparisons of Developmental $+1.5^{\circ} \mathrm{C}$ and $+3.0^{\circ} \mathrm{C}$ and their corresponding Control treatment (Supplementary Figure 1). This is consistent with the results of the LRT described above, where the highest proportion of DEGs were found between the F1 and F2 generations. There was, however, some overlap among the top GO categories activated for Developmental $+1.5^{\circ} \mathrm{C}$ and $+3.0^{\circ} \mathrm{C}$ in both generations, indicating similar molecular processes were activated among many of the comparisons. For example, 64 categories that overlapped between Control vs. Developmental $+1.5^{\circ} \mathrm{C}$ for the F1 and the F2 generations (Supplementary Data 3). GO terms associated with the electron transport chain ("Electron transport chain," "Electron transfer activity," "Respiratory chain complex"), energy metabolism ("ATP metabolic process"), oxidation-reduction ("Oxidoreductase complex," "Oxidoreductase activity"), and circadian regulation ("Circadian regulation of gene expression”), were activated in Control (Supplementary Data 2). Meanwhile, ion channel activity ("Sodium channel activity," "Gated channel activity"), cellular structure ("Myosin Complex," "Cell-cell adhesion," "Motor Activity," "Cell junction organization"), signal transduction ("Semaphorin-plexin signaling pathway," "Signaling receptor activity," "Protein kinase activity," "Enzyme linked receptor protein signaling pathway," "Cell surface receptor signaling pathway") and regulation of transcription ("Transcription regulator complex") were activated for Developmental $+1.5^{\circ} \mathrm{C}$ treatments of both generations. Meanwhile for the comparison of Developmental $+3.0^{\circ} \mathrm{C}$, there were 10 overlapping categories. Here, categories such as "Hormone activity," "Receptor ligand activity" and "Signaling receptor binding" were activated in
Control. The two categories activated for Developmental $+3.0^{\circ} \mathrm{C}$ of F1 and F2 were associated with organization of microtubules ("Dynein complex") and oxidation-reduction ("2-oxoglutaratedependent dioxygenase activity"). This suggests that some of the molecular processes that are being activated in both the F1 and F2 developmental treatments are part of a common response to the same level of warming, and that overlap of categories is higher for samples exposed to $+1.5^{\circ} \mathrm{C}$.

The GO enrichment analyses also revealed considerable overlap between Developmental (F1 and F2) and Transgenerational (F2) treatments exposed to $+1.5^{\circ} \mathrm{C} \quad(63$ categories; Supplementary Data 3). Activated categories at $+1.5^{\circ} \mathrm{C}$ included regulation of signal transduction, extracellular signaling, regulation of the rate of organismal process, myosin activation, sodium channel activity and motor activity. Meanwhile, downregulated GO terms for several of $+1.5^{\circ} \mathrm{C}$ categories included: ATP metabolic process, electron transfer, respiratory chain complex, and hormone activity. In contrast, there was little overlap between GO categories activated in the Developmental and Transgenerational treatments exposed to $+3.0^{\circ} \mathrm{C}$, as only four categories overlapped across the $\mathrm{F} 1$ and F2 generations (Supplementary Data 3). This could be associated with the cross-generational acclimation seen for samples of the F2, as well as the uniqueness of the Step $+3.0^{\circ} \mathrm{C}$ treatment which had a progressive warming across generations. Some of the of the GO categories that were activated in both Developmental and Transgenerational $+3.0^{\circ} \mathrm{C}$ treatments of the F2 were associated with dioxygenase activity (oxidoreductase), organization of organelles, synthesis of nucleic acids, chromatin organization, response to DNA damage and cellular response to stimulus. Interestingly, the GO terms "Regulation of Heart Rate" and "Neuropeptide Hormone Activity" were downregulated among all the $+3.0^{\circ} \mathrm{C}$ experimental groups compared to the control group.

There was also some level of overlap between the Transgenerational $+3.0^{\circ} \mathrm{C}$ and Step $+3.0^{\circ} \mathrm{C}$, as 49 annotated genes overlapped between the comparison of F2 Transgenerational $+1.5^{\circ} \mathrm{C}$ vs. Step $+3.0^{\circ} \mathrm{C}$ and $\mathrm{F} 2$ Transgenerational $+1.5^{\circ} \mathrm{C}$ vs. Transgenerational $+3.0^{\circ} \mathrm{C}$. This included the activation of genes involved with cellcycle progression and proliferation (Cyclin-1; Breast cancer anti-estrogen resistance 3), immunity and wound healing (Immunoglobulin lambda constant 1; Fibronectin), inflammation (Keratin, type II cytoskeletal 8), cellular organization (Septin-7; Myosin regulatory light polypeptide 9; Centrosome and spindle pole-associated protein 1), oxygen transport (Myoglobin), detoxification (S-formylglutathione hydrolase), and protein folding during stress response (Stress-associated endoplasmic reticulum protein 1) for fish exposed to $+3.0^{\circ} \mathrm{C}$ treatments.

\section{DISCUSSION}

Developmental and transgenerational plasticity are relevant mechanisms of aerobic and reproductive compensation in marine organisms, including coral reef fishes. Since these mechanisms can operate on short time scales (months to 
years), they can confer faster compensation when compared to adaptation by natural selection or genetic rescue from warm-adapted populations (Donelson et al., 2019). Despite recent advances, our understanding of the effects of warming, potential mechanisms of compensation and associated molecular responses in marine fishes remains limited for organs of important centralized function, such as the brain. Here, we show that exposure to warming promotes changes in gene expression associated with protein folding, oxygen transport (i.e., myoglobin), apoptosis and cell death, modification of cellular structure, mitochondrial activity, immunity and changes in circadian regulation. There was also a large difference in the transcriptional program of individuals for the F1 and F2 generations, suggesting that differences in parental history (wild-caught for F1 generation and captivereared for F2 generation) can have a considerable effect on brain gene expression. The results also show that the brain gene expression can be influenced by the intensity of warming (i.e., $+1.5^{\circ} \mathrm{C}$ vs. $+3.0^{\circ} \mathrm{C}$ ) as well as the history of exposure to elevated temperatures (i.e., developmental vs. transgenerational treatments), as demonstrated by the pairwise contrasts within the F1 and F2 generations. Below we discuss the general molecular processes activated with temperature increase, the pathways associated with the developmental and transgenerational response, as well as the intermediate response observed for individuals exposed to step-wise warming.

\section{Differences Between Generations}

The largest differences in expression were observed between F1 and F2 individuals. Considering individuals of both groups were exposed to the same temperatures, it is challenging to pin-point the mechanisms involved with these large differences in expression. Previous studies have shown changes in gene expression and epigenetic marks as a response to captivity, for species such as steelhead trout (Oncorhynchus mykiss; Christie et al., 2016), coho salmon (O. kisutch; Le Luyer et al., 2017), and brook charr (Salvelinus fontinalis; Sauvage et al., 2010). These studies reported significant differences for genes involved with immunity, protein catabolism, oxidative phosphorylation, glycolysis, citric acid cycle, fatty acid metabolism, synaptic signal modulations, and neuromuscular communication (Roberge et al., 2006; Sauvage et al., 2010; Christie et al., 2016; Le Luyer et al., 2017; Uusi-Heikkilä et al., 2017), all of which were differentiated in our comparisons. In the present study with A. polyacanthus, the most plausible explanation for the differences in gene expression are the contrasts in ecological history of the parents, as F1 fish had wild-caught parents, whereas F2 fish had parents that fully developed in captivity. This was corroborated by the large number of DEGs observed between Control F1 and F2 individuals, which were not exposed to any changes in temperature. In other words, parental effects related to differences in the environmental and ecological conditions experienced by the parents appear to have substantial effects on the brain of their offspring. Adult fish reared entirely in captivity would have vastly different experiences (i.e., food supply, ecological interactions, habitat complexity, space use and activity) compared with adult fish collected from the wild, even if their thermal histories are similar. We hypothesize that these differences in the ecological histories of the parents are responsible for the very large number of DEGs in the brain between F1 and F2 fish that have otherwise experienced identical conditions. Interestingly, the number of DEGs observed here in the brain of Control F1 and F2 fish $(7,500)$ was many times higher than previous experiments in liver for the same species (Veilleux et al., 2015; Bernal et al., 2018), suggesting that the effect of different parental ecological histories has a large effect on the brain when compared to other tissues. Moreover, most of the genes that were differentiated between F1 and F2 control were also differentially expressed in the LRT of all F1 and F2 treatments (6,326 DEGs).

Due to the controlled nature of the experiment there are few other variables that could be influencing the large differences in expression between F1 and F2. These include: changes in allele frequency between the two generations as a result of selective breeding and/or selective mortality; and differences in the proportion of males and females between generations. Differences in gene expression as a result of selective breeding have been previously reported in fishes (e.g., Eizaguirre et al., 2012; Uusi-Heikkilä et al., 2017), yet this is highly unlikely in our experiment given that monogamous breeding pairs were formed at random (i.e., aiming for diverse crosses between family lines). This limits the impact from sexual selection pressures that could create biases in the distribution of alleles across generations. Still, we did see some evidence of F1 pairs that reproduced in $+3^{\circ} \mathrm{C}$ being comprised of one individual from a single F0 line (Donelson et al., 2012), which contributed to the effect of F0 breeding pairs. Yet the number of DEGs that can be attributed to grandparents is relatively modest compared (268 DEGs) to the large number of DEGs between generations (11,060 DEGs). Further, the similarity in gene expression between Transgenerational and Step $+3^{\circ} \mathrm{C}$ and other treatments suggested this selection through breeding is not playing a decisive role in our results (similar results also seen in previous studies with liver: Veilleux et al., 2015; Bernal et al., 2018). The experiment also started with a small number of pairs $(n=8)$ collected in the same area of Palm Island, and subsequent changes across generations would not have a large effect on overall diversity. Further, selection due to mortality at elevated temperatures also had a negligible effect, as recorded deaths were low $(<5 \%)$ across all treatments during the experiments with $A$. polyacanthus. Thus, mortality in the $+1.5^{\circ} \mathrm{C}$ and $+3.0^{\circ} \mathrm{C}$ treatments was not larger to what was observed in Control, which is similar to what has been observed in previous experiments with the same species (e.g., Donelson et al., 2012). Finally, there was a slightly larger proportion of females in the F2 relative to the F1. Several studies in fishes have found dozens to hundreds of genes differentiated between male and female brains (Santos et al., 2008; Schunter et al., 2014), yet in our study it appears to be negligible (8 DEGs). Thus, the main explanation between differences in the F1 and F2 still appears to be acclimation to captivity. We are not aware of any other studies that have 
examined molecular responses of the brains of fish from wildcaught versus captive-reared parents, and this would be a valuable avenue of research to better understand the physiological effects of captivity.

\section{General Effects of Temperature on Fish Brains}

The patterns of brain gene expression evaluated in this study show evidence for activation of processes such as oxidoreductase activity, mitochondrial activity, oxygen transport, ion channel regulation/formation, and immunity in responses to warming. Results observed in the brain concur with the previous observations in the liver, where genes associated with reactive oxygen species, apoptosis, immunity, mitochondrial activity, and cell death are activated at warmer temperatures (Veilleux et al., 2015; Bernal et al., 2018). These patterns could be associated with the increase in resting oxygen consumption at warmer temperatures in A. polyacanthus (Donelson et al., 2012; Veilleux et al., 2015; Bernal et al., 2018). Even when aerobic compensation across generations can lead to similar aerobic scope between control and transgenerational treatments, it appears that the slight increase in aerobic demand at rest for individuals exposed to warm temperatures has a direct effect on the molecular processes of both liver and brain.

The increase in aerobic demand is also evidenced by the activation or suppression of genes associated with oxygen delivery and heart function. One of the more salient findings from the experiment was the activation of the gene Myoglobin $(M B)$ in several of the $+1.5^{\circ} \mathrm{C}$ and $+3.0^{\circ} \mathrm{C}$ treatments. In general, $M B$ is an oxygen-binding protein, and its activation in brain, muscle, heart and liver has been previously associated with tolerance to hypoxic conditions (Fraser et al., 2006). There is also evidence that $M B$ is activated as a mechanism of protection against the accumulation of nitric oxide and reactive oxygen species in the brain, liver, and muscle in fish (Cossins et al., 2009). Similarly, the GO term "Hemoglobin Complex" was upregulated across multiple Developmental and Transgenerational treatments, further supporting the need to supply the elevated oxygen demand associated with higher temperatures. In this case, it is possible that exposure to warmer conditions triggers protective roles to enhance oxygen delivery in the brain, as well as processing reactive oxygen species that could be generated by increased oxygen consumption. In contrast, one of the GO terms that was intensely downregulated among all the $+3.0^{\circ} \mathrm{C}$ experimental groups of the $\mathrm{F} 2$ when compared to the Control was "Regulation of heart rate." This could be a stress response corresponding to the elevated heart rates needed to maintain the aerobic demands generated by elevated temperatures.

Multiple functions were shared for treatments at $+1.5^{\circ} \mathrm{C}$ and $+3.0^{\circ} \mathrm{C}$, yet they appear to be attenuated in the latter. For example, comparisons associated with the $+3.0^{\circ} \mathrm{C}$ showed activation for the gene Stress-associated endoplasmic reticulum protein 1 (SERP1). This chaperon protein was discovered by subjecting rat neuronal cells to hypoxia, which in turn leads to an increase in unfolded proteins when the endoplasmic reticulum is under stress (Yamaguchi et al., 1999). Overall, SERP1 could be playing a beneficial role for individuals exposed to warmer temperature treatment, as it would protect proteins that are being formed from degradation at elevated temperatures. The gene G2/M phase-specific E3 ubiquitin-ligase (G2E3) has been associated with protection against DNA damage during the G2 phase of the mitosis, and is known to be activated in the presence of toxins that can affect chromosomal structure (Brooks et al., 2007). There were also cases where the signatures of cell death and apoptosis were observed at both temperatures for both Transgenerational and Developmental treatments. For example, there was evidence for the activation of the gene Tumor necrosis factor receptor superfamily member $10 B$ (TNFRSF10B), which play an important role in the activation of the caspase signaling cascade that mediates apoptosis of the endoplasmic reticulum under stressful conditions, leading to cell death (Kominami et al., 2012). This gene has also been associated with the response to low levels of oxygen in fish ovaries (Tse et al., 2015). Perhaps the strongest association with apoptosis is the activation of Annexin A5 in most $+3.0^{\circ} \mathrm{C}$ treatments. This gene is a membranebinding protein which serves as a signal for apoptosis, and is extensively used in vertebrates for the detection of cell death after hypoxic stress (including strokes in humans; Mussunoor and Murray, 2008). Overall, there appears to be concordance between some of thermal stress responses observed in both brain and liver of A. polyacanthus (Bernal et al., 2018), as protein synthesis regulation, protection against DNA damage and cell death/apoptosis are all characteristic traits of organisms exposed to increased aerobic demand as a result of exposure to warm conditions.

The results from this study also show that higher temperatures can produce changes in the organization of the cytoskeleton, as multiple genes and corresponding GO categories were activated in both Developmental and Transgenerational treatments at both elevated temperatures. Studies suggest that the maintenance of the cellular structure under warm conditions can be crucial for the preservation of motility, signaling, and muscle control (via ATP turn-over rates; Garland et al., 2015; Madeira et al., 2017). Further, modifications of the cytoskeleton are one of the main mechanisms for shifting the volume and shape of neuronal cells in vertebrates (Sunnerberg et al., 2019). Cytoskeletal modifications have been reported in zebrafish brains as a result of exposure to cold and warm temperature (Nonnis et al., 2021), and given the distant relationship between this species and A. polyacanthus, it is likely this is a general response of bony fishes to thermal fluctuations.

Finally, the GO term "Circadian regulation of expression" was downregulated for most warm Developmental and Transgenerational treatments with respect to Control. This is consistent with previous observations in both poikilothermic and homeothermic organisms, where the primary two factors influencing circadian regulation are light availability and temperature (Kominami et al., 2012). Studies suggest that changes in activity levels throughout the day are associated with mechanisms for optimizing energy utilization in the face of thermal variations (Hut et al., 2012). This response is highly plastic in vertebrates, and in extreme cases of temperature 
variation it can lead nocturnal mammals to develop diurnal patterns of activity (van der Vinne et al., 2014). In the particular case of A. polyacanthus, it is possible that changes in patterns of daily activity are a mechanism for compensation to elevated temperatures, yet behavioral observations are pending.

\section{Processes Activated at the Developmental Level}

Despite the low overlap between specific genes activated for individuals of the F1 and F2, there was evidence for concordance of the enriched GO categories between the Developmental treatments of both generations, suggesting similar processes are being activated. Categories such as regulation of gene expression ("Covalent chromatin modification," "Transcription regulator activity," "Transcription regulator complex"), DNA replication ("DNA metabolic process, DNA replication," "Chromosome organization"), and protein synthesis ("Protein-containing complex binding," "Protein-DNA complex," "Protein-containing complex subunit organization") were activated in most Developmental categories with respect to Control. Thus, they could be considered some of the most general responses to temperature increase during development. There was, however, higher similarity in molecular functions between generations when warming was "moderate" at $+1.5^{\circ} \mathrm{C}$, when compared to $+3.0^{\circ} \mathrm{C}$ treatments. This suggests that more intense warming can promote a diverse molecular response in fish brains, which should be considered as we aim to predict responses for marine ectotherms to ocean warming in coming decades.

There were also processes that were only seen in one of the generations. For example, the F2 Developmental $+1.5^{\circ} \mathrm{C}$ treatment showed downregulation for GO categories related with energetic balance (e.g., "ATP metabolic process," "Electron transfer activity," "Generation of precursor metabolites and energy," "Mitochondrial protein-containing complex," "Mitochondrion and Proton-transporting two-sector ATPase complex"), and cellular communication ("Cellular Signaling and Organization," "Signal Transduction," and "Cell Migration"), which were not differentially enriched in F1 fish. Even when downregulation of energy balance and cellular communication has previously been documented as a result of temperature increase (damselfishes livers: Kassahn et al., 2007; Bernal et al., 2018; zebrafish brains, Toni et al., 2019), it is surprising that the deactivation was not observed in the F1. Additionally, F2 Developmental $+3.0^{\circ} \mathrm{C}$ experienced the activation of regulatory processes including heart rate, appetite, and energy, which may represent a response to a challenging thermal environment, but these changes were not observed in the first generation. Another specific mechanism for compensation observed in the F2 Developmental $+1.5^{\circ} \mathrm{C}$ treatment was the activation of the GO category "Vascular endothelial growth factor-activated receptor activity," with respect to Control. Genes associated with this category are tightly associated with the formation of new blood vessels in the brain, and these functions are known to be significantly activated under hypoxic conditions in human brains (Marti et al., 2000). It is unclear why this highly relevant category was not found to be significantly up- or down- regulated in any other experimental group comparisons, highlighting the differences observed with temperature intensity and thermal history. When translated to future environmental predictions we see that these developmental stages are highly plastic (e.g., Dahlke et al., 2020), and that differences in the magnitude of warming $\left(+1.5\right.$ vs. $\left.+3.0^{\circ} \mathrm{C}\right)$ can lead to large differences in molecular pathways activated in the brain.

\section{Processes Associated With Transgenerational Treatments}

A decrease in synaptic activity for transgenerational treatments at $+3.0^{\circ} \mathrm{C}$ was consistently observed. For example, the GO term "Synapse" was downregulated in Transgenerational $+3.0^{\circ} \mathrm{C}$ and Step $+3.0^{\circ} \mathrm{C}$ with regards to Control. In addition, genes in the category Neuropeptide Hormone Activity were downregulated for all Transgenerational treatments $(+1.5$ and $+3.0^{\circ} \mathrm{C}$ ) including Step, when compared to Control. This is in contrast to the activation of genes associated with synaptic activity we observed for Transgenerational $+1.5^{\circ} \mathrm{C}$, which also showed activation for the categories associated with the physical structure of the synapses, including: "Regulation of Synapse Organization" and "Regulation of Synapse Maturation." The results of the synaptic activity coincide with the observations for GO categories associated with ion channel activity (7 in total), which were downregulated for Step and Transgenerational $+3.0^{\circ} \mathrm{C}$, but upregulated for Transgenerational $+1.5^{\circ} \mathrm{C}$. These categories were also differentially expressed across some of the Developmental treatments, but the largest differences were observed for the cross-generational groups, suggesting that there is a differential effect associated with length of exposure to higher temperature. Changes in temperature between generations are also influencing neurotransmission, as processes associated with synaptic activity and neuronal organization were upregulated in Transgenerational $+3.0^{\circ} \mathrm{C}$ when compared to Step $+3.0^{\circ} \mathrm{C}$.

These molecular results are in line with behavioral and physiological studies that suggest temperature will affect synaptic activity and the behavior of fishes. Previous studies in goldfish have demonstrated that the intensity for neuronal impulses can change dramatically with just a couple of degrees Celsius, and that the maximum synaptic activity depends on the temperature that the fish have been acclimated to Friedlander et al. (1976). This has been corroborated by more recent studies, where measurements of synaptic activity of M-cells in goldfish acclimated to warm temperature $\left(25^{\circ} \mathrm{C}\right)$ showed imbalances in the inhibition and excitation of synapses, when compared to acute exposure to colder temperatures $\left(5^{\circ} \mathrm{C}\right.$ and $15^{\circ} \mathrm{C}$; Szabo et al., 2008). These differences in synaptic activity in goldfish led to less coordination in the direction of escapes, which could result in more frequent encounter with predators (Szabo et al., 2008). Studies in coral reef fishes have shown that escape behavior is directly affected as a result of sensory performance, and acute warming can lead to the inhibition of burst escape responses (Warren et al., 2017) and to escape a shorter distance from the predator (Allan et al., 2015). Our results suggest the intensity and duration of warming are influencing neuronal transmission in A. polyacanthus, which 
could be associated with changes in escape behaviors observed in other fish species.

Despite the downregulation of synaptic activity, there appears to be a signature for the development of neuromotor connections at elevated temperature. One of the more salient examples in terms of individuals genes associated with neuronal development was the activation of Plastin 3 (PLS3) in the Transgenerational $+3.0^{\circ} \mathrm{C}$ treatment. PLS3 is an actin binding protein that is known to help with the formation and development of axons in vertebrate models, which can help restore synaptic function and motor-neuron connections under stress (Oprea et al., 2008; Alrafiah et al., 2018). This gene has been identified as a potential therapeutic for muscular dystrophy in humans, mice and zebrafish as it provides a protective role for individuals with mutations of survival motor neuron 1 gene (SMN1; Oprea et al., 2008; Kaifer et al., 2017). Similar results have also been observed in Drosophila, where the neuromotor junction develops faster in larvae at higher temperatures (Ueda and $\mathrm{Wu}, 2015$ ).

One of the detrimental outcomes of extended warm exposure of the transgenerational treatments was the activation of genes and GO terms associated with hemolysis, (e.g., DELTAthalatoxin-Avl1a, Transgenerational $+1.5^{\circ} \mathrm{C}$; DELTA-alicitoxinPselb, Transgenerational $+1.5^{\circ} \mathrm{C}$ and $+3.0^{\circ} \mathrm{C}$; Stonustoxin subunit alpha, Transgenerational $+3.0^{\circ} \mathrm{C}$ ). These proteins are important components of fish venoms that can produce considerable tissue damage and death via the destruction of red blood cells (Chen et al., 1997; Silva et al., 2018). Increased metabolic activity is known to produce hemolysis as a result on the increase of oxidative stress. It is possible that the destruction of erythrocytes is taking place in neuronal cells as a result of increased aerobic demand during warming conditions.

The F2 experimental design of this study represents an opportunity to evaluate the effects of absolute temperature, crossgenerational temperature change and the duration of exposure (i.e., within or across generations) on fish brains. This is mostly thanks to the Step treatment, and the differences in relation to other treatments in the F2 generation. Comparing both Developmental treatments to the Step $+3.0^{\circ} \mathrm{C}$, resulted in a small number of DEGs (17 DEGs $+1.5^{\circ} \mathrm{C}$; 2 DEGs $+3.0^{\circ} \mathrm{C}$ ). This is comparable to the differences observed between Step $+3.0^{\circ} \mathrm{C}$ and Developmental $+3.0^{\circ} \mathrm{C}$ in the liver (12 DEG; Bernal et al., 2018). Since all treatments experienced an increase in temperature at hatching, these similarities potentially indicate that warming experienced early in life can result in similar gene expression changes in both brain and liver. We also observed small differences between Step $+3.0^{\circ} \mathrm{C}$ and Transgenerational $+3.0^{\circ} \mathrm{C}$ groups (2 DEGs), which experience different exposures across generations but similar absolute temperature in the current generation. This pattern was very different to what was previously reported for liver (123 DEGs; Bernal et al., 2018). Considering that the comparison between Development $+3.0^{\circ} \mathrm{C}$ and Transgenerational $+3.0^{\circ} \mathrm{C}$ resulted in $32 \mathrm{DEGs}$, it seems that Step $+3.0^{\circ} \mathrm{C}$ is exhibiting an intermediate response. This supports the idea that both absolute temperature and experiencing thermal change in early life heavily influence brain gene expression. There was a relatively large difference when comparing Step $+3.0^{\circ} \mathrm{C}$ with their siblings in Transgenerational $+1.5^{\circ} \mathrm{C}$ (149 DEGs). This number was large in comparison to all other Step $+3.0^{\circ} \mathrm{C}$ comparisons, and compared to Transgenerational $+1.5^{\circ} \mathrm{C}$ and Control (50 DEGs). These results suggest that the brain is especially sensitive to temperature change across generations, compared to the liver. Overall, breaking down the effects of warming depending on the context of experience requires further investigation, but the overlap in metabolic processes observed between the liver and brain is a relevant result for future considerations of the effects of temperature increase on coral reef fishes.

\section{CONCLUSION}

The results from this study suggest that there is a tremendous plasticity in brain gene expression, which can complicate efforts to predict how this central organ will respond to future thermal conditions. Here, we report that there was a sizeable effect of parental acclimation to captivity in fish brains, as the largest differences in expression were observed between the F1 and F2 generation (including the Control treatments), which differed mostly in the history of their parents (wild-caught versus captive reared). There was also a significant effect caused by warming, where genes related to cellular stress and energy metabolism were differentially expressed across developmental and transgenerational treatments. Many of these processes have been previously identified to be differentially expressed in liver of the same species, showing that multiple tissues could respond similarly to the increased physiological and metabolic demand associated with warming. At higher temperatures, there was also evident downregulation of neurotransmission and synaptic activity, which have the potential to influence fish behavior as temperatures increase. This downregulation was most apparent for the step-wise warming treatment, suggesting that frequent changes in temperature across generations could be particularly influential on neuro-transmission. Some of the more salient pathways related with compensation to warming were associated with toxin metabolism, changes in cellular structure, oxygen transport and increase in neuro-motor associations. Finally, our results indicate that the intensity of warming has an effect on how divergent the molecular responses will be in upcoming decades, as the overlap in molecular functions was higher for $+1.5^{\circ} \mathrm{C}$ treatments than for $+3.0^{\circ} \mathrm{C}$ treatments. Overall, this study exemplifies how the molecular responses of fish brains can be influenced by both the intensity of warming, as well as the history of thermal exposure.

\section{DATA AVAILABILITY STATEMENT}

The datasets presented in this study can be found in online repositories. The names of the repository/repositories and accession number(s) can be found below: Raw sequences can be found in NCBI through accession number PRJNA768249. Bioinformatic scripts are available in Github: https://github.com/schmidte10/GO-MWU-automation- and https://github.com/evofish/f2-brains. 


\section{ETHICS STATEMENT}

The animal study was reviewed and approved by James Cook University animal ethics approvals A1233, A1415, and A1547.

\section{AUTHOR CONTRIBUTIONS}

JD and PM conceived the study. JD conducted the experiments with live fish. $\mathrm{MB}$ and TR organized samples, and sequencing and data distribution. MB and ES analyzed the data. All authors contributed to the writing and approved the final version of the manuscript.

\section{FUNDING}

Funds for this project were provided by the King Abdullah University of Science and Technology to TR and PM. JD was supported by an ARC Future Fellowship (FT190100015).

\section{REFERENCES}

Alfonso, S., Gesto, M., and Sadoul, B. (2021). Temperature increase and its effects on fish stress physiology in the context of global warming. J. Fish Biol. 98, 1496-1508. doi: 10.1111/jfb.14599

Allan, B. J. M., Domenici, P., Munday, P. L., and McCormick, M. I. (2015). Feeling the heat: the effect of acute temperature changes on predator-prey interactions in coral reef fish. Conserv. Physiol. 3:cov011. doi: 10.1093/conphys/cov011

Alrafiah, A., Karyka, E., Coldicott, I., Iremonger, K., Lewis, K. E., Ning, K., et al. (2018). Plastin 3 promotes motor neuron axonal growth and extends survival in a mouse model of spinal muscular atrophy. Mol. Ther. Methods Clin. Dev. 9, 81-89. doi: 10.1016/j.omtm.2018.01.007

Angiulli, E., Pagliara, V., Cioni, C., Frabetti, F., Pizzetti, F., Alleva, E., et al. (2020). Increase in environmental temperature affects exploratory behavior, anxiety and social preference in Danio rerio. Sci. Rep. 10:5385. doi: 10.1038/s41598020-62331- 1

Babkiewicz, E., Surga, K., Gliwicz, Z. M., and Maszczyk, P. (2021). The effect of temperature on the spatial learning rate of zebrafish (Danio rerio). Ethology 127, 632-642. doi: 10.1111/eth.13197

Beaman, J. E., White, C. R., and Seebacher, F. (2016). Evolution of plasticity: mechanistic link between development and reversible acclimation. Trends Ecol. Evol. 31, 237-249. doi: 10.1016/j.tree.2016.01.004

Bernal, M. A., Donelson, J. M., Veilleux, H. D., Ryu, T., Munday, P. L., and Ravasi, T. (2018). Phenotypic and molecular consequences of stepwise temperature increase across generations in a coral reef fish. Mol. Ecol. 27, 4516-4528. doi: $10.1111 / \mathrm{mec} .14884$

Bernal, M. A., Schunter, C., Lehmann, R., Lightfoot, D. J., Allan, B. J. M., Veilleux, H. D., et al. (2020). Species-specific molecular responses of wild coral reef fishes during a marine heatwave. Sci. Adv. 6, 3423-3441. doi: 10.1126/sciadv.aay3423

Bilyk, K. T., and DeVries, A. L. (2011). Heat tolerance and its plasticity in Antarctic fishes. Comp. Biochem. Physiol. Part A Mol. Integr. Physiol. 158, 382-390. doi: 10.1016/j.cbpa.2010.12.010

Braithwaite, V. A. (2006). Cognitive ability in fish. Fish Phys. 24:1. doi: 10.1098/ rspb.2013.1331

Brooks, W. S., Banerjee, S., and Crawford, D. F. (2007). G2E3 is a nucleocytoplasmic shuttling protein with DNA damage responsive localization. Exp. Cell Res. 313, 665-676. doi: 10.1016/j.yexcr.2006.11.020

Burgess, S. C., and Marshall, D. J. (2014). Adaptive parental effects: the importance of estimating environmental predictability and offspring fitness appropriately. Oikos 123, 769-776. doi: 10.1111/oik.01235

Chen, D., Kini, R. M., Yuen, R., and Khoo, H. E. (1997). Haemolytic activity of stonustoxin from stonefish (Synanceja horrida) venom: pore formation and the

\section{ACKNOWLEDGMENTS}

We would like to acknowledge the team at JCU who provided the technical support for the aquarium rearing. D. Lightfoot who provided support with extractions and organization of the samples. The Alabama Supercomputer Authority for providing support with computational resources to $\mathrm{MB}$.

\section{SUPPLEMENTARY MATERIAL}

The Supplementary Material for this article can be found online at: https://www.frontiersin.org/articles/10.3389/fmars. 2022.784418/full\#supplementary-material. Supplementary Data Tables 1, 2, 3 for DEGs and GO categories are available at: https://figshare.com/articles/dataset/Supplementary_Data_ for_Gene_Expression_of_Fish_Brains_-_Bernal_et_al_2021/ 17192861 .

role of cationic amino acid residues. Biochem. J. 325, 685-691. doi: 10.1042/ bj3250685

Christie, M. R., Marine, M. L., Fox, S. E., French, R. A., and Blouin, M. S. (2016). A single generation of domestication heritably alters the expression of hundreds of genes. Nat. Comm. 7, 1-6. doi: 10.1038/ncomms10676

Cossins, A. (2012). Temperature Biology Of Animals. Berlin: Springer Science \& Business Media.

Cossins, A. R., Williams, D. R., Foulkes, N. S., Berenbrink, M., and Kipar, A. (2009). Diverse cell-specific expression of myoglobin isoforms in brain, kidney, gill and liver of the hypoxia-tolerant carp and zebrafish. J. Exp. Biol. 212, 627-638. doi: 10.1242/jeb.026286

Cummings, M. E. (2015). The mate choice mind: studying mate preference, aversion and social cognition in the female poeciliid brain. Anim. Behav. 103, 249-258. doi: 10.1016/j.anbehav.2015.02.021

da Silva, C. R. B., Riginos, C., and Wilson, R. S. (2019). An intertidal fish shows thermal acclimation despite living in a rapidly fluctuating environment. J. Comp. Physiol. B 189, 385-398. doi: 10.1007/s00360-019-01212-0

da Silva-Pinto, T., Silveira, M. M., de Souza, J. F., Moreira, A. L. P., Vieira, E. A., Longo, G. O., et al. (2020). Damselfish face climate change: impact of temperature and habitat structure on agonistic behavior. PLoS One 15:e0235389. doi: 10.1371/journal.pone.0235389

Dahlke, F. T., Wohlrab, S., Butzin, M., and Pörtner, H.-O. (2020). Thermal bottlenecks in the life cycle define climate vulnerability of fish. Science 369, 65-70. doi: 10.1126/science.aaz3658

Donelson, J. M., McCormick, M. I., Booth, D. J., and Munday, P. L. (2014). Reproductive acclimation to increased water temperature in a tropical reef fish. PLoS One 9:e97223. doi: 10.1371/journal.pone.0097223

Donelson, J. M., Munday, P. L., McCormick, M. I, Pankhurst, N. W., and Pankhurst, P. M. (2010). Effects of elevated water temperature and food availability on the reproductive performance of a coral reef fish. Mar. Ecol. Prog. Ser. 401, 233-243.

Donelson, J. M., Munday, P. L., McCORMICK, M. I., and Nilsson, G. E. (2011). Acclimation to predicted ocean warming through developmental plasticity in a tropical reef fish. Glob. Change Biol. 17, 1712-1719. doi: 10.1111/j.1365-2486. 2010.02339.x

Donelson, J. M., Munday, P. L., McCormick, M. I., and Pitcher, C. R. (2012). Rapid transgenerational acclimation of a tropical reef fish to climate change. Nat. Clim. Change 2, 30-32. doi: 10.1038/nclimate1323

Donelson, J. M., Sunday, J. M., Figueira, W. F., Gaitán-Espitia, J. D., Hobday, A. J., Johnson, C. R., et al. (2019). Understanding interactions between plasticity, adaptation and range shifts in response to marine environmental change. Philos. Trans R Soc. Lond. B Biol. Sci. 374:20180186. doi: 10.1098/rstb.2018.0186 
Donelson, J. M., Wong, M., Booth, D. J., and Munday, P. L. (2016). Transgenerational plasticity of reproduction depends on rate of warming across generations. Evol. Appl. 9, 1072-1081. doi: 10.1111/eva.12386/full

Eizaguirre, C., Lenz, T. L., Kalbe, M., and Milinski, M. (2012). Divergent selection on locally adapted major histocompatibility complex immune genes experimentally proven in the field. Ecol. Lett. 15, 723-731. doi: 10.1111/j.14610248.2012.01791

Eliason, E. J., Clark, T. D., Hague, M. J., Hanson, L. M., Gallagher, Z. S., Jeffries, K. M., et al. (2011). Differences in thermal tolerance among sockeye salmon populations. Science 332, 109-112. doi: 10.1126/science.1199158

Fox, R. J., Donelson, J. M., Schunter, C., Ravasi, T., and Gaitán-Espitia, J. D. (2019). Beyond buying time: the role of plasticity in phenotypic adaptation to rapid environmental change. Philos. Trans. R Soc. Lond. B Biol. Sci. 374:20180174. doi: 10.1098/rstb.2018.0174

Fraser, J., de Mello, L. V., Ward, D., Rees, H. H., Williams, D. R., Fang, Y., et al. (2006). Hypoxia-inducible myoglobin expression in nonmuscle tissues. Proc. Natl. Acad. Sci. U.S.A. 103, 2977-2981. doi: 10.1073/pnas.0508270103

Friedlander, M. J., Kotchabhakdi, N., and Prosser, C. L. (1976). Effects of cold and heat on behavior and cerebellar function in goldfish. J. Comp. Physiol. 112, 19-45. doi: 10.1007/BF00612674

Fry, F. J. (1967). "Responses of vertebrate poikilotherms to temperature," in Thermobiology, ed. A. H. Rose (London: Academic Press), 375-409.

Garland, M. A., Stillman, J. H., and Tomanek, L. (2015). The proteomic response of cheliped myofibril tissue in the eurythermal porcelain crab Petrolisthes cinctipes to heat shock following acclimation to daily temperature fluctuations. J. Exp. Biol. 218, 388-403. doi: 10.1242/jeb.112250

Grenchik, M. K., Donelson, J. M., and Munday, P. L. (2013). Evidence for developmental thermal acclimation in the damselfish, Pomacentrus moluccensis. Coral Reefs 32, 85-90. doi: 10.1007/s00338-012-0949-1

He, G., Liu, X., Xu, Y., Liang, J., Deng, Y., Zhang, Y., et al. (2021). Repeated exposure to simulated marine heatwaves enhances the thermal tolerance in pearl oysters. Aquat. Toxicol. 239:105959. doi: 10.1016/j.aquatox.2021.105959

Hobday, A. J., and Lough, J. M. (2011). Projected climate change in Australian marine and freshwater environments. Mar. Freshw. Res. 62, 1000-1014. doi: $10.1071 / \mathrm{mf} 10302$

Huey, R. B., and Kingsolver, J. G. (1989). Evolution of thermal sensitivity of ectotherm performance. Trends Ecol. Evol. 4, 131-135. doi: 10.1016/01695347(89)90211-5

Hut, R. A., Kronfeld-Schor, N., van der Vinne, V., and De la Iglesia, H. (2012). In search of a temporal niche: environmental factors. Prog. Brain Res. 199, 281-304. doi: 10.1016/B978-0-444-59427-3.00017-4

Kah, O., Anglade, I., Leprêtre, E., Dubourg, P., and de Monbrison, D. (1993). The reproductive brain in fish. Fish Physiol. Biochem. 11, 85-98.

Kaifer, K. A., Villalón, E., Osman, E. Y., Glascock, J. J., Arnold, L. L., Cornelison, D. D. W., et al. (2017). Plastin-3 extends survival and reduces severity in mouse models of spinal muscular atrophy. JCI Insight 2:e89970. doi: 10.1172/ jci.insight. 89970

Kassahn, K. S., Crozier, R. H., Ward, A. C., Stone, G., and Caley, M. J. (2007). From transcriptome to biological function: environmental stress in an ectothermic vertebrate, the coral reef fish Pomacentrus moluccensis. BMC Genomics 8:358. doi: 10.1186/1471-2164-8-358

Kim, D., Langmead, B., and Salzberg, S. L. (2015). HISAT: a fast spliced aligner with low memory requirements. Nat. Meth. 12, 357-360. doi: 10.1038/nmeth. 3317

Kominami, K., Nakabayashi, J., Nagai, T., Tsujimura, Y., Chiba, K., Kimura, H., et al. (2012). The molecular mechanism of apoptosis upon caspase-8 activation: quantitative experimental validation of a mathematical model. Biochim Biophys Acta Mol Cell Res 1823, 1825-1840. doi: 10.1016/j.bbamcr.2012.07.003

Kotrschal, K., Van Staaden, M. J., and Huber, R. (1998). Fish brains: evolution and and environmental relationships. Rev. Fish. Biol. Fish. 8, 373-408. doi: 10.1023/A:1008839605380

Le Luyer, J., Laporte, M., Beacham, T. D., Kaukinen, K. H., Withler, R. E., Leong, J. S., et al. (2017). Parallel epigenetic modifications induced by hatchery rearing in a Pacific salmon. Proc. Natl. Acad. Sci. U.S.A. 114, 12964-12969. doi: 10.1073/ pnas. 1711229114

Liao, Y., Smyth, G. K., and Shi, W. (2014). featureCounts: an efficient general purpose program for assigning sequence reads to genomic features. Bioinformatics 30, 923-930. doi: 10.1093/bioinformatics/btt656
Long, Y., Li, L., Li, Q., He, X., and Cui, Z. (2012). Transcriptomic characterization of temperature stress responses in larval zebrafish. PLoS One 7:e37209. doi: 10.1371/journal.pone.0037209

Lough, J. M. (2007). "Chapter 02: climate and climate change on the great barrier reef," in Climate Change And The Great Barrier Reef: A Vulnerability Assessment, eds J. E. Johnson and P. Marshall (Townsville QLD: The Great Barrier Reef Marine Park Authority).

Love, M. I., Huber, W., and Anders, S. (2014). Moderated estimation of fold change and dispersion for RNA-seq data with DESeq2. Genome Biol. 15:550. doi: 10.1186/s13059-014-0550-8

Madeira, C., Madeira, D., Diniz, M. S., Cabral, H. N., and Vinagre, C. (2016). Thermal acclimation in clownfish: an integrated biomarker response and multitissue experimental approach. Ecol. Indic. 71, 280-292. doi: 10.1016/j.ecolind. 2016.07.009

Madeira, D., Araújo, J. E., Vitorino, R., Costa, P. M., Capelo, J. L., Vinagre, C., et al. (2017). Molecular plasticity under ocean warming: proteomics and fitness data provides clues for a better understanding of the thermal tolerance in fish. Front. Physiol. 8:825. doi: 10.3389/fphys.2017.00825

Madeira, D., Narciso, L., Cabral, H. N., Vinagre, C., and Diniz, M. S. (2013). Influence of temperature in thermal and oxidative stress responses in estuarine fish. Comp. Biochem. Physiol. Part A Mol. Integr. Physiol. 166, 237-243. doi: 10.1016/j.cbpa.2013.06.008

Marti, H. J., Bernaudin, M., Bellail, A., Schoch, H., Euler, M., Petit, E., et al. (2000). Hypoxia-induced vascular endothelial growth factor expression precedes neovascularization after cerebral ischemia. Am. J. Pathol. 156, 965-976. doi: $10.1016 /$ S0002-9440(10)64964-4

Martin, M. (2011). Cutadapt removes adapter sequences from high-throughput sequencing reads. EMBnet J. 17, 10-12. doi: 10.14806/ej.17.1.200

McArley, T. J., Hickey, A. J. R., and Herbert, N. A. (2017). Chronic warm exposure impairs growth performance and reduces thermal safety margins in the common triplefin fish (Forsterygion lapillum). J. Exp. Biol. 220, 3527-3535. doi: $10.1242 /$ jeb.162099

Munday, P. L., Jones, G. P., Pratchett, M. S., and Williams, A. J. (2008). Climate change and the future for coral reef fishes. Fish Fish. 9, 261-285. doi: 10.1111/j. 1467-2979.2008.00281.x

Munday, P. L., Warner, R. R., Monro, K., Pandolfi, J. M., and Marshall, D. J. (2013). Predicting evolutionary responses to climate change in the sea. Ecol. Lett. 16, 1488-1500. doi: 10.1111/ele.12185

Mussunoor, S., and Murray, G. I. (2008). The role of annexins in tumour development and progression. J. Pathol. 216, 131-140. doi: 10.1002/path.2400

Nilsson, G. E., Östlund-Nilsson, S., and Munday, P. L. (2010). Effects of elevated temperature on coral reef fishes: loss of hypoxia tolerance and inability to acclimate. Comp. Biochem. Physiol. Part A Mol. Integr. Physiol. 156, 389-393. doi: 10.1016/j.cbpa.2010.03.009

Nonnis, S., Angiulli, E., Maffioli, E., Frabetti, F., Negri, A., Cioni, C., et al. (2021). Acute environmental temperature variation affects brain protein expression, anxiety and explorative behavior in adult zebrafish. Sci. Rep. 11:2521. doi: 10. 1038/s41598-021-81804-5

Okuzawa, K., and Gen, K. (2013). High water temperature impairs ovarian activity and gene expression in the brain-pituitary-gonadal axis in female red seabream during the spawning season. Gen. Comp. Endocrinol. 194, 24-30. doi: 10.1016/ j.ygcen.2013.08.015

Oprea, G. E., Kröber, S., McWhorter, M. L., Rossoll, W., Müller, S., Krawczak, M., et al. (2008). Plastin 3 is a protective modifier of autosomal recessive spinal muscular atrophy. Science 320, 524-527. doi: 10.1126/science.1155085

Pachauri, R. K., Meyer, L., Plattner, G.-K., Stocker, T., et al. (2015). IPCC, 2014: Climate Change 2014: Synthesis Report. Contribution of Working Groups I, II and III to the Fifth Assessment Report of the Intergovernmental Panel on Climate Change. Geneva: IPCC.

Pankhurst, N. W., and Munday, P. L. (2011). Effects of climate change on fish reproduction and early life history stages. Mar. Freshw. Res. 62, 1015-1026. doi: 10.1071/MF10269

Pankhurst, N. W., Hilder, P. I., and Pankhurst, P. M. (1999). Reproductive condition and behavior in relation to plasma levels of gonadal steroids in the spiny damselfish Acanthochromis polyacanthus. Gen. Comp. Endocrinol. 115, 53-69. doi: 10.1006/gcen.1999.7285

Podrabsky, J. E., and Somero, G. N. (2004). Changes in gene expression associated with acclimation to constant temperatures and fluctuating daily temperatures 
in an annual killifish Austrofundulus limnaeus. J. Exp. Biol. 207, 2237-2254. doi: $10.1242 /$ jeb. 01016

Pörtner, H. O., and Farrell, A. P. (2008). Physiology and climate change. Science 322, 690-692. doi: 10.1016/j.virol.2017.08.015

Pörtner, H. O., and Knust, R. (2007). Climate change affects marine fishes through the oxygen limitation of thermal tolerance. Science 315, 95-97. doi: 10.1126/ science. 1135471

R Core Team (2013). R: A Language And Environment For Statistical Computing. Vienna: R Core Team.

Randall, J. E., Allen, G. R., and Steene, R. C. (1997). Fishes Of The Great Barrier Reef And Coral Sea. Honolulu, HI: University of Hawaii Press, 580.

Rebl, A., Verleih, M., Nipkow, M., Altmann, S., Bochert, R., and Goldammer, T. (2018). Gradual and acute temperature rise induces crossing endocrine, metabolic, and immunological pathways in maraena whitefish (Coregonus maraena). Front. Genet. 9:241. doi: 10.3389/fgene.2018.00241

Rey, S., Digka, N., and MacKenzie, S. (2015). Animal personality relates to thermal preference in wild-type zebrafish, Danio rerio. Zebrafish 12, 243-249. doi: 10. 1089/zeb.2014.1076

Roberge, C., Einum, S., Guderley, H., and Bernatchez, L. (2006). Rapid parallel evolutionary changes of gene transcription profiles in farmed Atlantic salmon. Mol. Ecol. 15, 9-20. doi: 10.1111/j.1365-294X.2005.02807.x

Robinson, E., and Davison, W. (2008). The Antarctic notothenioid fish Pagothenia borchgrevinki is thermally flexible: acclimation changes oxygen consumption. Polar Biol. 31, 317-326. doi: 10.1007/s00300-007-0361-4

Ross, P. M., Parker, L., and Byrne, M. (2016). Transgenerational responses of molluscs and echinoderms to changing ocean conditions. ICES J. Mar. Sci. 73, 537-549. doi: 10.1093/icesims/fsv254

Salinas, S., and Munch, S. B. (2012). Thermal legacies: transgenerational effects of temperature on growth in a vertebrate. Ecol. Lett. 15, 159-163. doi: 10.1111/j. 1461-0248.2011.01721.x

Sandoval-Castillo, J., Gates, K., Brauer, C. J., Smith, S., Bernatchez, L., and Beheregaray, L. B. (2020). Adaptation of plasticity to projected maximum temperatures and across climatically defined bioregions. Proc. Natl. Acad. Sci. U.S.A. 117, 17112-17121. doi: 10.1073/pnas.1921124117

Santos, E. M., Kille, P., Workman, V. L., Paull, G. C., and Tyler, C. R. (2008). Sexually dimorphic gene expression in the brains of mature zebrafish. Comp. Biochem. Physiol. Part A Mol. Integr. Physiol. 149, 314-324. doi: 10.1016/j.cbpa. 2008.01.010

Sauvage, C., Derôme, N., Normandeau, E., St-Cyr, J., Audet, C., and Bernatchez, L. (2010). Fast transcriptional responses to domestication in the brook charr Salvelinus fontinalis. Genetics 185, 105-112. doi: 10.1534/genetics.110.115071

Schulte, P. M., Healy, T. M., and Fangue, N. A. (2011). Thermal performance curves, phenotypic plasticity, and the time scales of temperature exposure. Integr. Comp. Biol. 51, 691-702. doi: 10.1093/icb/icr097

Schunter, C., Vollmer, S. V., Macpherson, E., and Pascual, M. (2014). Transcriptome analyses and differential gene expression in a non-model fish species with alternative mating tactics. BMC Genomics 15:167. doi: 10.1186/ 1471-2164-15-167

Schunter, C., Welch, M. J., Ryu, T., Zhang, H., Berumen, M. L., Nilsson, G. E., et al. (2016). Molecular signatures of transgenerational response to ocean acidification in a species of reef fish. Nat. Clim. Change 6, 1014-1018. doi: 10.1038/nclimate3087

Shama, L. N., Strobel, A., Mark, F. C., and Wegner, K. M. (2014). Transgenerational plasticity in marine sticklebacks: maternal effects mediate impacts of a warming ocean. Funct. Ecol. 28, 1482-1493. doi: 10.1111/jeb.12490

Silva, F., Huang, Y., Yang, V., Mu, X., Shi, Q., and Antunes, A. (2018), Transcriptomic characterization of the south american freshwater stingray potamotrygon motoro venom apparatus. Toxins 10:544. doi: 10.3390/ toxins 10120544

Somero, G. N. (2010). The physiology of climate change: how potentials for acclimatization and genetic adaptation will determine 'winners' and 'losers.' J. Exp. Biol. 213, 912-920. doi: 10.1242/jeb.037473

Stillman, J. H. (2004). A comparative analysis of plasticity of thermal limits in porcelain crabs across latitudinal and intertidal zone clines. Int. Congr. 1275, 267-274. doi: 10.1016/j.ics.2004.09.034

Sunnerberg, J. P., Moore, P., Spedden, E., Kaplan, D. L., and Staii, C. (2019). Variations of elastic modulus and cell volume with temperature for cortical neurons. Langmuir 35, 10965-10976. doi: 10.1021/acs.langmuir. 9b01651

Szabo, T. M., Brookings, T., Preuss, T., and Faber, D. S. (2008). Effects of temperature acclimation on a central neural circuit and its behavioral output. J. Neurophysiol. 100, 2997-3008. doi: 10.1152/jn.91033.2008

Toni, M., Angiulli, E., Miccoli, G., Cioni, C., Alleva, E., Frabetti, F., et al. (2019). Environmental temperature variation affects brain protein expression and cognitive abilities in adult zebra fish (Danio rerio): a proteomic and behavioral study. J. Proteom 204:103396. doi: 10.1016/j.jprot.2019.103396

Torda, G., Donelson, J. M., Aranda, M., Barshis, D. J., Bay, L., Berumen, M. L., et al. (2017). Rapid adaptive responses to climate change in corals. Nat. Clim. Change 7, 627-636. doi: 10.1038/nclimate3374

Tse, A. C.-K., Li, J.-W., Chan, T.-F., Wu, R. S.-S., and Lai, K.-P. (2015). Hypoxia induces miR-210, leading to anti-apoptosis in ovarian follicular cells of marine medaka Oryzias melastigma. Aquat. Toxicol. 165, 189-196. doi: 10.1016/j. aquatox.2015.06.002

Ueda, A., and Wu, C.-F. (2015). The role of cAMP in synaptic homeostasis in response to environmental temperature challenges and hyperexcitability mutations. Front. Cell Neurosci. 9:10. doi: 10.3389/fncel.2015.00010

Uusi-Heikkilä, S., Sävilammi, T., Leder, E., Arlinghaus, R., and Primmer, C. R. (2017). Rapid, broad-scale gene expression evolution in experimentally harvested fish populations. Mol. Ecol. 26, 3954-3967. doi: 10.1111/mec.14179

van der Vinne, V., Riede, S. J., Gorter, J. A., Eijer, W. G., Sellix, M. T., Menaker, M., et al. (2014). Cold and hunger induce diurnality in a nocturnal mammal. Proc. Natl. Acad. Sci. U.S.A. 111, 15256-15260. doi: 10.1073/pnas.1413135111

Veilleux, H. D., Donelson, J. M., and Munday, P. L. (2018). Reproductive gene expression in a coral reef fish exposed to increasing temperature across generations. Conserv. Physiol. 6, 1-12. doi: 10.1093/conphys/cox077

Veilleux, H. D., Ryu, T., Donelson, J. M., Van Herwerden, L., Seridi, L., Ghosheh, Y. et al. (2015). Molecular processes of transgenerational acclimation to a warming ocean. Nat. Clim. Change 5, 1074-1078. doi: 10.1038/nclimate2724

Warren, D. T., and McCormick, M. I. (2019). Intrageneric differences in the effects of acute temperature exposure on competitive behavior of damselfishes. PeerJ 7:e7320. doi: 10.7717/peerj.7320

Warren, D. T., Donelson, J. M., and McCormick, M. I. (2017). Extended exposure to elevated temperature affects escape response behavior in coral reef fishes. PeerJ 5:e3652. doi: 10.7717/peerj.3652

Winberg, S., Arthur, A., Myrberg, J., and Nilsson, G. E. (1996). Agonistic interactions affect brain serotonergic activity in an acanthopterygiian fish: the bicolor damselfish (Pomacentrus partitus). BBE 48, 213-220. doi: 10.1159/ 000113199

Wright, R. M., Aglyamova, G. V., Meyer, E., and Matz, M. V. (2015). Gene expression associated with white syndromes in a reef building coral, Acropora hyacinthus. BMC Genomics 16:371. doi: 10.1186/s12864-015-1540-2

Yamaguchi, A., Hori, O., Stern, D. M., Hartmann, E., Ogawa, S., and Tohyama, M. (1999). Stress-associated endoplasmic reticulum protein 1 (Serp1)/ribosomeassociated membrane protein 4 (ramp4) stabilizes membrane proteins during stress and facilitates subsequent glycosylation. J. Cell Biol. 147, 1195-1204. doi: $10.1083 /$ jcb.147.6.1195

Conflict of Interest: The authors declare that the research was conducted in the absence of any commercial or financial relationships that could be construed as a potential conflict of interest.

Publisher's Note: All claims expressed in this article are solely those of the authors and do not necessarily represent those of their affiliated organizations, or those of the publisher, the editors and the reviewers. Any product that may be evaluated in this article, or claim that may be made by its manufacturer, is not guaranteed or endorsed by the publisher.

Copyright () 2022 Bernal, Schmidt, Donelson, Munday and Ravasi. This is an openaccess article distributed under the terms of the Creative Commons Attribution License (CC BY). The use, distribution or reproduction in other forums is permitted, provided the original author(s) and the copyright owner(s) are credited and that the original publication in this journal is cited, in accordance with accepted academic practice. No use, distribution or reproduction is permitted which does not comply with these terms. 